\title{
Coevolution of Mucosal Immunoglobulins and the Polymeric Immunoglobulin Receptor: Evidence That the Commensal Microbiota Provided the Driving Force
}

\author{
Charlotte S. Kaetzel \\ Department of Microbiology, Immunology and Molecular Genetics, University of Kentucky College of Medicine, \\ 203 Combs Cancer Research Building, 800 Rose Street, Lexington, KY 40536, USA
}

Correspondence should be addressed to Charlotte S. Kaetzel; cskaet@uky.edu

Received 25 November 2013; Accepted 29 December 2013; Published 4 March 2014

Academic Editors: M. C. Béné and J. L. Stafford

Copyright (C) 2014 Charlotte S. Kaetzel. This is an open access article distributed under the Creative Commons Attribution License, which permits unrestricted use, distribution, and reproduction in any medium, provided the original work is properly cited.

\begin{abstract}
Immunoglobulins (Igs) in mucosal secretions contribute to immune homeostasis by limiting access of microbial and environmental antigens to the body proper, maintaining the integrity of the epithelial barrier and shaping the composition of the commensal microbiota. The emergence of IgM in cartilaginous fish represented the primordial mucosal Ig, which is expressed in all higher vertebrates. Expansion and diversification of the mucosal Ig repertoire led to the emergence of IgT in bony fishes, IgX in amphibians, and IgA in reptiles, birds, and mammals. Parallel evolution of cellular receptors for the constant ( $\mathrm{Fc}$ ) regions of Igs provided mechanisms for their transport and immune effector functions. The most ancient of these Fc receptors is the polymeric Ig receptor (pIgR), which first appeared in an ancestor of bony fishes. The pIgR transports polymeric IgM, IgT, IgX, and IgA across epithelial cells into external secretions. Diversification and refinement of the structure of mucosal Igs during tetrapod evolution were paralleled by structural changes in pIgR, culminating in the multifunctional secretory IgA complex in mammals. In this paper, evidence is presented that the mutualistic relationship between the commensal microbiota and the vertebrate host provided the driving force for coevolution of mucosal Igs and pIgR.
\end{abstract}

\section{Introduction}

The mucosal surfaces of the body form the primary interface with the outside world, providing a conduit for intake of nutrients and air and a home for beneficial microbes that act as "extended self" [1]. Host cells that populate mucosal surfaces must carry out the challenging task of maintaining a mutualistic relationship with the resident microbiota, while protecting the body proper against potential pathogens, toxic environmental substances, and soluble dietary antigens that could act as systemic allergens. Adaptive immune systems, characterized by clonally expressed, somatically diversified antigen receptors in lymphocytes, first emerged in a common ancestor of modern vertebrates [2,3] (Figure 1). Jawless fish of the superclass Agnatha (hagfishes and lampreys) generate variable-like receptors (VLRs) for antigen (Ag) by a mechanism involving gene conversion. The evolution of the RAG1/2 dependent mechanism of $\mathrm{V}(\mathrm{D}) \mathrm{J}$ somatic recombination in an ancestor of modern jawed vertebrates led to the first appearance of Ag-specific immunoglobulins (Igs) and Tcell antigen receptors $[4,5]$. The basic structural unit of Igs comprises 2 identical light chains, encoded by IGL genes, and 2 identical heavy chains, encoded by $I G H$ genes (Figure 2). The polypeptide chains of Ig light and heavy chains consist of repeating units of approximately 110 amino acids, socalled "Ig-like" domains with a characteristic 3-dimensional structure $[6,7]$. Each domain is encoded by a single exon, suggesting that the $I G L$ and $I G H$ genes evolved by duplication and diversification of a primordial Ig-like gene. Ig light chains comprise an $\mathrm{N}$-terminal variable $\left(\mathrm{V}_{\mathrm{L}}\right)$ domain followed by a constant $\left(C_{L}\right)$ domain of either the $\kappa$ or $\lambda$ type. Ig heavy chains comprise an $\mathrm{N}$-terminal variable domain $\left(\mathrm{V}_{\mathrm{H}}\right)$ followed by 3-4 constant domains $\left(\mathrm{C}_{\mathrm{H}} 1-\mathrm{C}_{\mathrm{H}} 3\right.$ or 4$)$. The sequence of Ig heavy chain constant regions (designated by Greek letters such as $\alpha, \gamma$, or $\mu$ ) defines the Ig class or isotype. Pairing of $\mathrm{V}_{\mathrm{H}}$ and $\mathrm{V}_{\mathrm{L}}$ domains on adjacent Ig heavy and light chains 


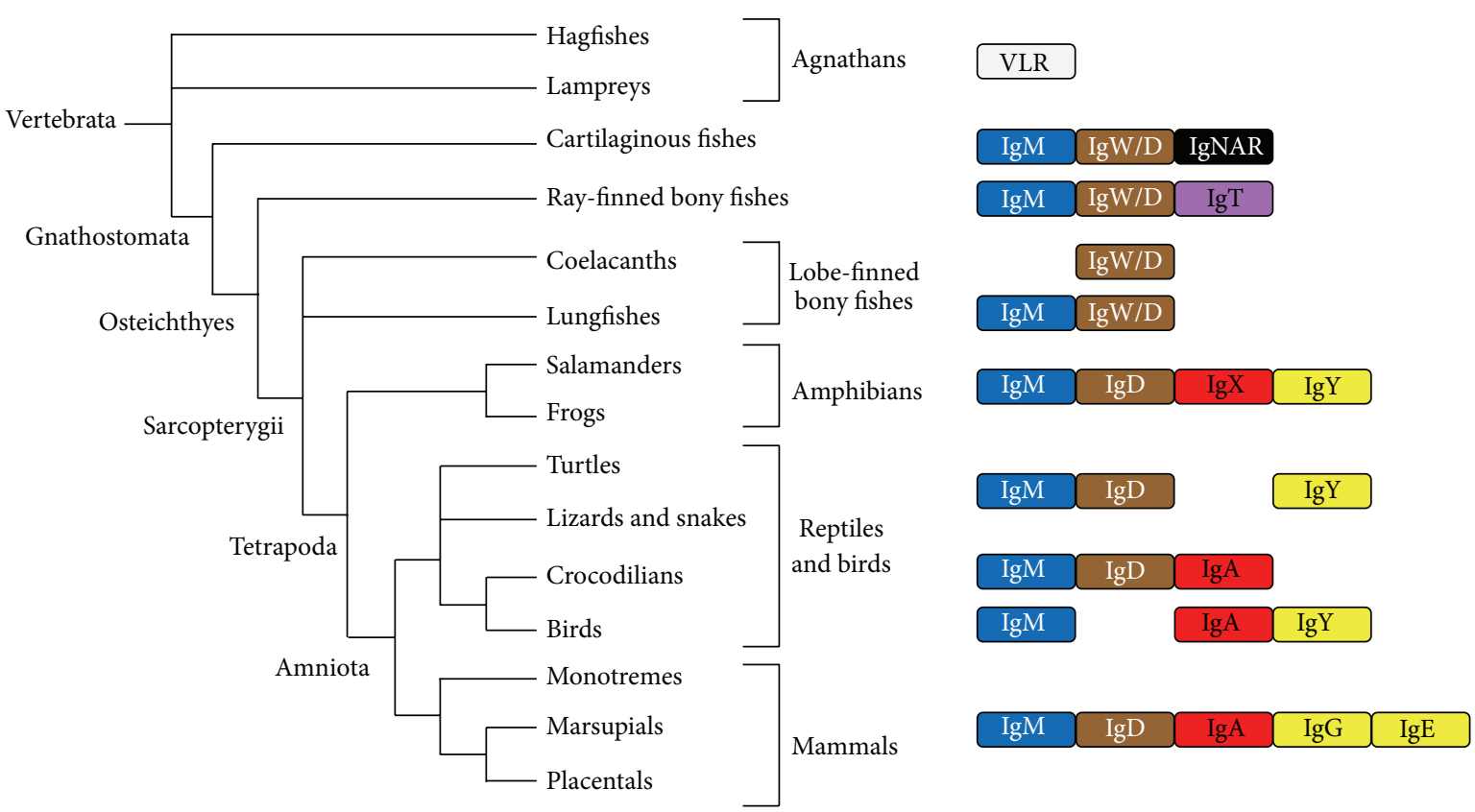

FIGURE 1: A model for evolution of immunoglobulin isotypes in vertebrates. The antigen-binding variable lymphocyte receptors (VLRs) expressed in extant Agnathans are thought to represent the precursors of modern immunoglobulins (Igs). Genes encoding Ig heavy and light chains apparently emerged prior to the split between cartilaginous and bony fishes, resulting in expression of Ig molecules that are characteristic of higher vertebrates. Cartilaginous fishes express an IgD-like molecule (IgW/D) and IgM, which is found evenly distributed between blood and mucosal secretions. The first evidence of a dedicated mucosal Ig isotype came with the emergence of IgT in an ancestor of modern bony fishes. Subsequent duplication of Ig constant region genes and evolution of Ig class switching mechanisms in a common ancestor of tetrapods allowed the production of multiple Ig isotypes during immune responses. Color coding indicates the presumed evolution of avian and mammalian IgA from a precursor of amphibian IgX and evolution of mammalian IgG and IgE from a precursor of amphibian IgY.

forms the antigen-binding site, while the Fc regions of the Ig heavy chains (comprising the two most C-terminal constant domains) confer isotype-specific immune effector functions. Some Ig isotypes can form higher-order polymers of the basic 4-chain unit, thus increasing the number of Ag-binding sites and enhancing Fc-mediated functions. The emergence of new Ig isotypes during vertebrate evolution allowed for diversification of Ig-mediated immune functions, including those specialized for mucosal surfaces (reviewed in [8]). Many Ig-mediated immune functions involve interactions with isotype-specific cellular receptors for the Fc region of Ig heavy chains (Figure 3). The most evolutionarily ancient Fc receptor is the polymeric Ig receptor (pIgR), a protein expressed selectively by mucosal and glandular epithelial cells that transports polymeric Igs into external secretions. It has been hypothesized that the complex relationship between the vertebrate host and its resident microbiota provided the driving force for evolution of the adaptive immune system $[1,5]$. In this review, the concept will be explored that an important consequence of this selective pressure was the coevolution of mucosal Igs and pIgR.

\section{Evolution of Mucosal Immunoglobulins}

2.1. Cartilaginous Fishes. Primordial Ig-like genes are believed to have arisen in a common ancestor of the Gnathostomata (jawed vertebrates) [2, 3] (Figure 1). The most primitive extant jawed vertebrates comprise the class Chondrichthyes (cartilaginous fishes), including sharks, rays, and skates. Multiple Ig isotypes have been identified in the horned shark (Heterodontus francisci) [18], nurse shark (Ginglymostoma cirratum) [19, 20], and several species of skates [21]. The primordial IgM of cartilaginous fishes is orthologous to the IgM of higher vertebrates, while a second Ig isotype, initially called IgW, is orthologous to $\operatorname{IgD}[22]$. A third Ig isotype identified in the nurse shark, called the Ig "new antigen receptor" (IgNAR), is homologous to IgM and $\mathrm{IgW} / \mathrm{D}$ but does not have an ortholog in higher vertebrates [19]. The IGH and IGL genes are dispersed throughout the genome of cartilaginous fish in hundreds of clusters, each representing an individual isotype $[18,21]$.

2.2. Bony Fishes. Major changes in the organization of $\mathrm{Ig}$ genes occurred during the emergence of the Teleostomi, the clade of jawed vertebrates that includes the superclasses Osteichthyes (bony fishes) and Tetrapoda (four-limbed vertebrates) (Figure 1). The dispersed IGH loci characteristic of cartilaginous fishes were replaced with a translocon organization, comprising a $5^{\prime}$ region of $\mathrm{V}_{\mathrm{H}}, \mathrm{D}_{\mathrm{H}}$, and $\mathrm{J}_{\mathrm{H}}$ gene segments encoding the Ig heavy chain variable region, followed by tandem $\mathrm{C}_{\mathrm{H}}$ gene segments encoding Ig heavy chain constant regions for different isotypes (reviewed in [23]). This translocation organization allows a B lymphocyte to "switch" production from one Ig heavy chain isotype to another 


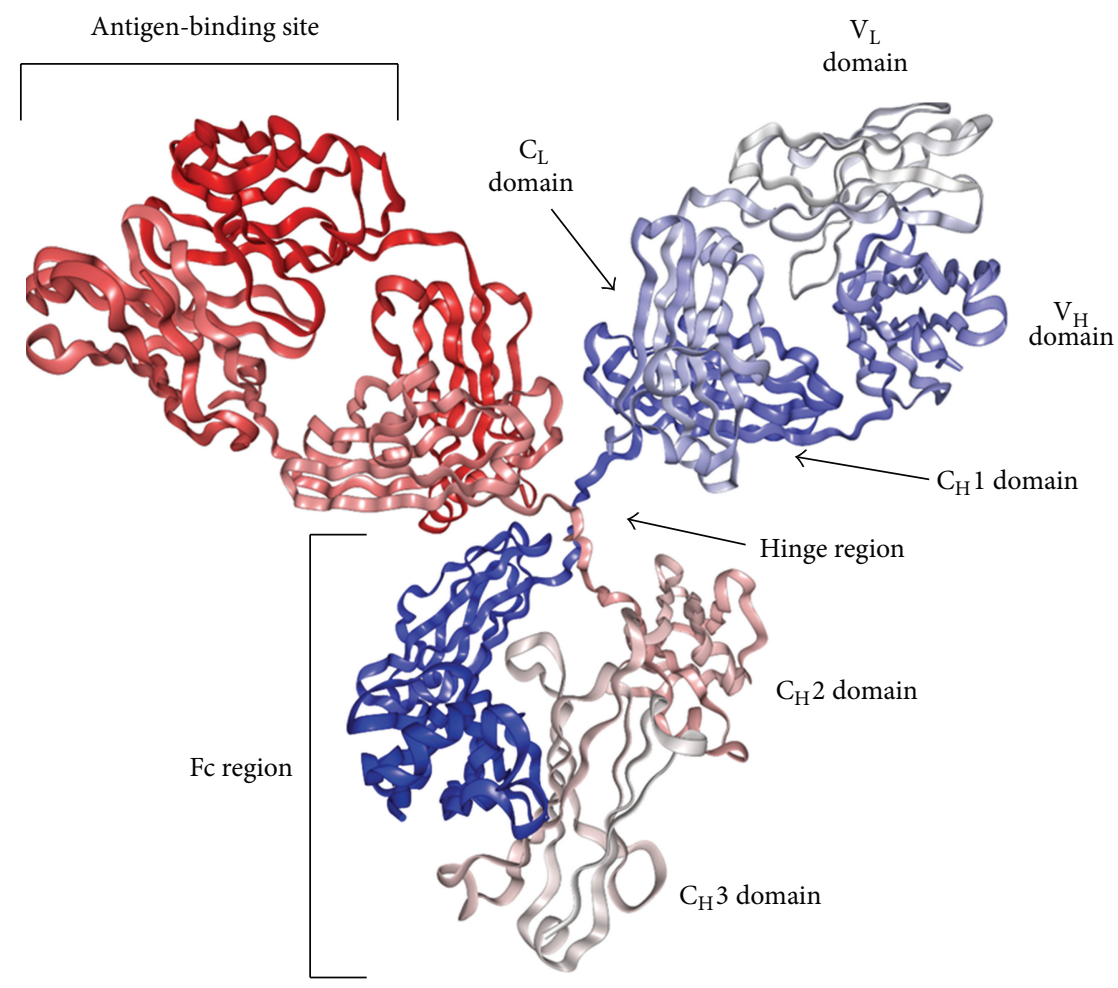

FIgURE 2: The basic structure of immunoglobulins. The basic structural unit of Igs comprises 2 identical light chains (shown in red and blue) and 2 identical heavy chains (shown in red and blue). The polypeptide chains of Ig light and heavy chains consist of repeating units of approximately 110 amino acids, so-called "Ig-like" domains with a characteristic 3-dimensional structure. Ig light chains comprise an Nterminal variable $\left(\mathrm{V}_{\mathrm{L}}\right)$ domain followed by a constant $\left(\mathrm{C}_{\mathrm{L}}\right)$ domain of either the $\kappa$ or $\lambda$ type. Ig heavy chains comprise an $\mathrm{N}$-terminal variable domain $\left(\mathrm{V}_{\mathrm{H}}\right)$ followed by 3-4 constant domains $\left(\mathrm{C}_{\mathrm{H}} 1-\mathrm{C}_{\mathrm{H}} 3\right.$ or 4$)$. The sequence of Ig heavy chain constant regions (designated by Greek letters such as $\alpha, \gamma$, or $\mu$ ) defines the Ig class or isotype. The structure shown here is characteristic of mammalian IgA, IgD, and IgG, in which the $\mathrm{C}_{\mathrm{H}} 1$ and $\mathrm{C}_{\mathrm{H}} 2$ domains of the heavy chains are connected by a short cysteine- and proline-rich hinge region. The structure of all Igs in lower vertebrates (as well as IgM and IgE in mammals) differs in that the $\mathrm{C}_{\mathrm{H}} 2$ domain replaces the hinge region and the $\mathrm{Fc}$ region comprises the $\mathrm{C}_{\mathrm{H}} 3$ and $\mathrm{C}_{\mathrm{H}} 4$ domains. Pairing of $\mathrm{V}_{\mathrm{H}}$ and $\mathrm{V}_{\mathrm{L}}$ domains on adjacent Ig heavy and light chains forms the antigen-binding site, while the $\mathrm{Fc}$ regions of the Ig heavy chains (comprising the two most C-terminal constant domains) confer isotype-specific immune effector functions.

during immune responses, by a process of DNA rearrangement called class switch recombination (CSR) [24-26]. Most of the studies of Ig structure and function in bony fishes have focused on the Actinopterygii (ray-finned bony fishes), which comprise $99 \%$ of the over 30,000 living species of fish, mainly within the infraclass Teleostei. Early studies in several teleost species, including plaice (Pleuronectes platessa) [27], common carp (Cyprinus carpio) [28], rainbow trout (Oncorhynchus mykiss) [29], and channel catfish (Ictalurus punctatus) [30], demonstrated that immunization by mucosal routes (oral, anal, and skin) elicited antibody responses in the skin, intestinal mucus, and bile. In 2005, a novel Ig isotype was described in rainbow trout [31], zebrafish (Danio rerio) [32], and fugu (Fugu rubripes) [33] designated IgT (for teleost) or IgZ (for zebrafish). In the same year, an unusual Ig isotype described in the common carp, which appeared to be a chimera of IgM and IgZ [34], was identified (Cyprinus carpio). Subsequent studies in a number of teleost species revealed a common translocon structure in the $I G H$ locus, with tandem gene segments encoding the constant regions of $\operatorname{IgM}, \operatorname{IgD}$, and $\operatorname{IgT}(\mathrm{Z})$ [35-37]. Functional studies revealed that the molar ratio of $\operatorname{IgT}$ to $\operatorname{IgM}$ was 60 -fold higher in gut mucus than in serum of rainbow trout and that specific IgT antibodies were induced in the gut following oral infection with the parasite Ceratomyxa shasta [38]. In this study, IgTexpressing lymphocytes were found to represent $54.3 \%$ of all $\mathrm{B}$ cells in the intestinal lamina propria. Interestingly, IgT was found as a monomer in serum but as a tetramer in gut mucus, suggestive of a selective mechanism for polymerization of IgT in mucosal B cells similar to that observed for IgA in higher vertebrates. Thus, IgT appears to be the most primitive Ig isotype with specialized functions at mucosal surfaces.

Although IgT has been identified in most Actinopterygii thus far studied, some exceptions have been noted. The absence of a gene encoding IgT was recently reported in the Siberian sturgeon (Acipenser baerii), a species of the order Acipenseriformes, which occupies a unique phylogenetic niche between the cartilaginous fishes and the Teleostei. The absence of IgT was also reported in the medaka (Oryzias latipes), a teleost of the order Beloniformes [39]. Surprisingly, IgT is absent in channel catfish, a teleost of the order Siluriformes, which is closely related to the order Cypriniformes 

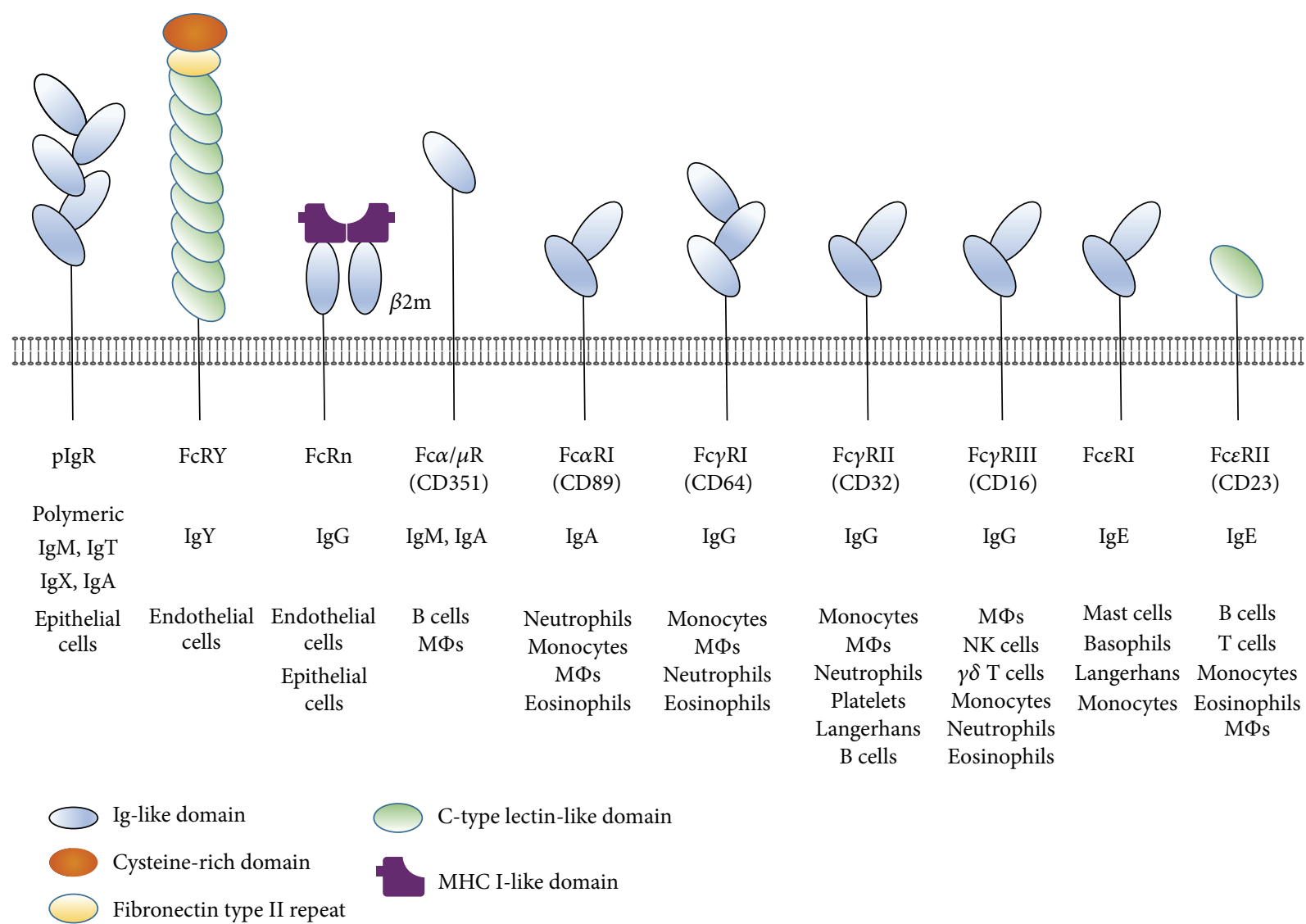

Figure 3: Fc receptors are Ig isotype- and cell type-specific. These schematic diagrams illustrate basic structural features of selected Fc receptors, all of which are Type I transmembrane proteins. The structures are not to scale and do not imply specific 3-dimensional conformations. All of the structures represent the human homolog of the indicated protein except for FcRY, which is from chicken. Binding of the constant $(\mathrm{Fc})$ region of Igs to cellular receptors initiates transport across epithelial cells or intracellular signaling in cells of hematopoietic origin. The membrane-proximal Ig-like domain of FcRn pairs with the Ig-like domain of soluble $\beta 2$-microglobulin $(\beta 2 \mathrm{~m})$. The Ig-binding subunits of Fc $\alpha$ RI, Fc $\gamma$ RI, Fc $\gamma$ RII, Fc $\gamma$ RIII, and FceRI (shown here) pair with other protein subunits (not shown) to initiate signaling pathways. This figure was compiled using information from [9-15].

that includes the IgT-expressing carp and zebrafish. The IGH loci of the few extant species of the class Sarcopterygii (lobefinned bony fishes, including coelacanths and lungfishes) differ from those of most of the Actinopterygii (Figure 1). The African coelacanth (Latimeria chalumnae), one of only two species of an ancient class of lobe-finned fishes, lacks IgM and has a single Ig heavy chain gene that resembles the IgW/D gene of cartilaginous fishes [40]. By contrast, the African lungfish (Protopterus aethiopicus) expresses both IgM and an isotype resembling IgW/D [41]. No ortholog of IgT has been identified in lobe-finned bony fishes. Given the diversity of Ig genes in bony fishes, the evolutionary origin of IgT remains obscure. Furthermore, while IgT shares many functional similarities with IgA in higher vertebrates, the structural genes for IgT and IgA are not orthologous [23]. Thus, the gene encoding $\operatorname{IgT}$ appears to be an evolutionary dead-end that emerged in some lineages of bony fishes in response to pressures for immunological protection of mucosal surfaces, likely driven by the resident microbiota as well as mucosal pathogens.
2.3. Amphibians. Duplication and diversification of gene segments within the $I G H$ locus in a common ancestor of the Tetrapoda (four-limbed vertebrates) led to the appearance of additional heavy chain Ig isotypes (reviewed in [42]) (Figure 1). Most extant species of tetrapods have a single IGH locus, the location of which is syntenic with the human IGH locus. Ectothermic vertebrates of the class Amphibia are the most primitive tetrapods, having diverged about 370 million years ago from a common ancestor with reptiles, birds, and mammals. Early studies of the structural and immunological properties of Igs from several species of clawed frogs (Xenopus) suggested the emergence of two novel Ig isotypes, IgX and IgY [43-47] (Figure 1). B cells expressing IgX, but not IgY, were found abundantly in the intestinal epithelium, whereas IgX-positive cells were rarely detected in the spleen and $\operatorname{IgX}$ levels were very low in serum [47]. Interestingly, thymectomy abolished expression of IgY, but not IgM or IgX, consistent with a T-independent role for IgX in the mucosal immune system of amphibians. Genes encoding $\operatorname{IgX}$ and $\operatorname{IgY}$ were subsequently identified in 2 species of salamanders [48, 49], 
suggesting that these Ig isotypes may have emerged in a common ancestor of amphibians. To date, no studies have been reported on $I G H$ loci in caecilians. A recent study in Xenopus laevis established the position of amphibian IgX as the evolutionary precursor of IgA in birds and mammals [50]. These investigators found that larval thymectomy did not affect levels of $\mathrm{IgX}$ and did not alter the composition of the gut microbiota, confirming the T-independence of the IgX response in Xenopus. Phylogenetic comparisons of IgT in bony fishes and $\operatorname{IgX}$ in amphibians suggest that these Ig isotypes evolved independently [23], likely responding to similar pressures from the resident microbiota and mucosal pathogens.

2.4. Reptiles and Birds. The clade Amniota within the superclass Tetrapoda can be subdivided into the sauropsids (reptiles and birds) and synapsids (mammals and their close relatives) (Figure 1). The distinction between reptiles and birds is based largely on physical characteristics rather than phylogeny, distinguishing the cold-blooded reptiles with scales from the warm-blooded birds with feathers. Early studies of Igs in turtles, lizards, and snakes were based largely on their physicochemical and antigenic properties, revealing a predominance of IgM and lesser amounts of IgY in bile and gut secretions [51-53]. Subsequent analyses using antibodies to chicken IgA failed to detect a cross-reactive Ig isotype in reptiles $[54,55]$. The recent availability of whole genome sequences for 2 species of turtles (Chrysemys picta and Pelodiscus sinensis) $[36,56]$ and the green anole lizard (Anolis carolinensis) [57] demonstrated the presence of gene segments encoding IgM, IgD, and multiple subclasses of IgY, but no ortholog of IgX in amphibians or IgA in birds and mammals. The leopard gecko (Eublepharis macularius) expresses $\operatorname{IgM}$, IgD, and a third Ig isotype that is intermediate in homology between $\operatorname{IgA}$ and $\operatorname{IgY}[50,58]$ (designated Ig "A" for the purposes of this review). The recent availability of whole genome sequences for 4 crocodilians (Alligator sinensis, Alligator mississippiensis, Crocodylus siamensis, and Crocodylus porosus) revealed significant differences in the IGH loci compared to other reptiles, including multiple subclasses of $\operatorname{IgM}$, IgD, and IgA (orthologous to the IgA genes of birds and mammals), but no $\operatorname{IgY}[59,60]$. Early studies of the immune systems of birds (class Aves) revealed the presence of an ortholog of mammalian IgA in mucosal secretions and an ortholog of IgG (designated IgY) in serum [61-69]. Mapping of the $I G H$ locus in chickens and ducks revealed an inverted gene segment encoding IgA, downstream of the IgM gene segment and upstream of the IgY gene segment, and loss of the gene segment encoding IgD [70, 71]. Availability of whole genome sequences for a variety of bird species in the National Center for Biotechnology Information (NCBI) database demonstrates the consistent presence of $\operatorname{IgM}, \operatorname{IgA}$, and IgY and the absence of IgD. A recent analysis of Ig gene transcripts in the ostrich (Struthio camelus) revealed similarities with chickens, ducks, and other birds, including the expression of $\operatorname{IgM}$, $\operatorname{IgA}$, and $\operatorname{IgY}$ and the absence of $\operatorname{IgD}$ [72]. Because the ostrich is one of the most primitive extant species of birds, it appears that the distinctive organization of the IGH locus evolved very early during the divergence of the avian lineage. Furthermore, a phylogenetic comparison of Ig heavy chain sequences from amphibians with those of higher vertebrates demonstrated with high statistical support that $\operatorname{IgX}$ from amphibians and $\operatorname{IgA}$ from birds share a recent common ancestor [50]. Taken together, the evidence is consistent with an IGH locus in a common ancestor of reptiles and birds that included gene segments encoding IgM, $\operatorname{IgD}, \operatorname{IgA}$, and IgY. Instability in the IGH locus in individual lineages apparently resulted in the selective loss of IgA in most turtles, lizards, and snakes, IgY in crocodilians, and IgD in birds.

2.5. Mammals. The structure of Ig genes and their encoded proteins has been studied extensively in extant species of the class Mammalia, including the egg-laying monotremes, the pouch-bearing marsupials, and the placentals (eutherians) (reviewed in [8]). The IGH locus in all known mammals is organized as a translocon with gene segments encoding $\operatorname{IgM}, \operatorname{IgD}, 2$ or more subclasses of IgG, 1 or more subclasses of $\operatorname{IgA}$, and $\operatorname{IgE}$, an isotype unique to mammals (Figure 1). A recent phylogenetic analysis of Ig heavy chain classes in tetrapods indicated with high statistical probability that the IgA gene(s) in mammals evolved from an IgX gene in a common ancestor of all tetrapods, while the IgG and IgE genes evolved more recently from IgY in a common ancestor of amniotes [50]. Continuing diversification in the IGH locus in mammals is evidenced by differences in the number of IgG and $\operatorname{IgA}$ subclasses and in the structure of Ig heavy chains. Unlike all Ig heavy chains in lower vertebrates, comprising 1 variable Ig-like domain $\left(\mathrm{V}_{\mathrm{H}}\right)$ and 4 constant Ig-like domains $\left(\mathrm{C}_{\mathrm{H}} 1-\mathrm{C}_{\mathrm{H}} 4\right)$, the $\mathrm{C}_{\mathrm{H}} 2$ domain in mammalian $\operatorname{IgA}$, IgD, and IgG was replaced with a short, flexible hinge region rich in cysteine and proline residues [73]. The heavy chain of mammalian IgE has retained the prototypic 4 constant Ig-like domains (as has IgM), suggesting that the evolution of the hinge region in mammalian IgG occurred after the evolution of IgG and IgE from an ancestral IgY gene (Figure 1).

Determination of the structure of the $I G H$ locus in the monotreme duck-billed platypus (Ornithorhynchus anatinus) revealed the presence of $8 \mathrm{C}_{\mathrm{H}}$ genes (including 2 subclasses of IgG and 2 subclasses of $\operatorname{IgG}$ ) arranged in the order $\mathrm{C}_{\mu^{-}}$ $\mathrm{C}_{\delta}-\mathrm{C}_{\mathrm{o}}-\mathrm{C}_{\gamma 2}-\mathrm{C}_{\gamma 1}-\mathrm{C}_{\alpha 1}-\mathrm{C}_{\varepsilon}-\mathrm{C}_{\alpha 2}[74,75]$. Interestingly, the gene encoding platypus IgD lacks a hinge region and is more similar in structure to $\operatorname{IgD}$ in lower vertebrates than the $\operatorname{IgD}$ of eutherian mammals. Downstream of the $\mathrm{C}_{\delta}$ gene in the platypus is a novel $\mathrm{C}_{\mathrm{o}}$ gene (omicron for Ornithorhynchus), which appears to have evolved from an ancestral IgY gene. In contrast to the platypus, only one IgA gene was identified in another monotreme, the echidna (Tachyglossus aculeatus), and in several species of marsupials [76-80]. Similarly, a single structural gene for IgA has been identified in 3 species of the eutherian order Rodentia, mouse (Mus musculus) [81], rat (Rattus norvegicus) (unpublished; Genbank accession number AJ510151), and gerbil (Meriones unguiculatus) [82]. By contrast, the $I G H$ locus in the European rabbit (Oryctolagus cuniculus, order Lagomorpha) is unique among mammals, apparently having evolved from a common ancestor 
prior to the divergence of marsupials and monotremes from eutherians. Distinctive features include a single IgG subclass, 13 functional IgA subclasses, and absence of $\operatorname{IgD}$ [83-85]. A more typical organization of the $I G H$ locus, including single subclasses of $\operatorname{IgM}, \operatorname{IgD}, \operatorname{IgA}$, and $\operatorname{IgE}$, and 2 subclasses of IgG has been reported in mammals of the orders Carnivora $[86,87]$, Cetartiodactyla (even-toed ungulates, whales, and dolphins) [88-91], and Perissodactyla (odd-toed ungulates) [92].

Mammals of the order Primates, including humans, have the greatest number and diversity of Ig classes and subclasses among all of the tetrapods. Mapping of IGH loci has now been completed for a number of primate species, including human (Homo sapiens), gorilla (Gorilla gorilla), chimpanzee (Pan troglodytes), orangutan (Pongo pygmaeus), gibbon (Hylobates lar), baboon (Papio anubis), mangabey (Cercocebus torquatus atys), and three species of macaques, the crab-eating monkey (Macaca fascicularis), pig-tailed monkey (Macaca nemestrina), and rhesus monkey (Macaca mulatta) [93-97]. A distinguishing feature of primates in the family Hominidae (great apes, including humans, gorillas, chimpanzees, and orangutans) and the family Hylobatidae (gibbons) is the presence of two IgA subclasses. Although the orangutan is a member of the family Hominidae, its $I G H$ locus contains only one IgA subclass gene, homologous to the IgA1 gene of other hominoids [95]. By contrast, primates in the family Cercopithecidae (Old World monkeys, including baboons, mangabeys, and macaques) have a single IgA gene. Genetic analysis of the IGH locus of primates suggested that duplication and diversification of the primordial $\mathrm{C}_{\gamma 1}-\mathrm{C}_{\gamma 2^{-}}$ $\mathrm{C}_{\varepsilon}-\mathrm{C}_{\alpha}$ region occurred in a common ancestor of the great apes after the divergence from Old World monkeys $[98,99]$. These events resulted in the current organization of the IGH locus in extant species of great apes, with four IgG subclasses and two $\operatorname{IgA}$ subclasses (the duplicated $\mathrm{C}_{\varepsilon}$ gene became a nonfunctional pseudogene; hence, only one class of $\operatorname{IgE}$ is expressed). The close phylogenetic relationship among the $\mathrm{C}_{\alpha}$ genes in the hominoids and Hylobatidae suggests that the $\mathrm{C}_{\alpha 1}$ and $\mathrm{C}_{\alpha 2}$ genes evolved from a single $\mathrm{C}_{\alpha}$ gene in a common ancestor of the great apes and that the $\mathrm{C}_{\alpha 2}$ gene was subsequently lost in the orangutan. Evidence of continuing evolution in the IGH locus of humans was demonstrated by the finding of triplication of the $\mathrm{C}_{\gamma 1}-\mathrm{C}_{\gamma 2}-\mathrm{C}_{\varepsilon}-\mathrm{C}_{\alpha}$ region in several families [100]. Subsequent genetic analyses in multiple ethnic groups revealed that gene duplications and deletions in the human IGH locus are surprisingly common, with frequencies up to $22 \%$ in Japanese and Chinese populations [101].

\section{Emergence of the IGJ Gene and Evolution of Polymeric Igs}

The ability to produce Igs as both monomers (i.e., one unit comprising 2 identical heavy chains and 2 identical light chains) and polymers (covalently linked aggregates of 2 or more Ig units) dates to the emergence of primitive Igs in cartilaginous fish $[23,42,50]$. Whereas pentameric IgM is typically found in serum as well as secretions, the polymeric forms of $\operatorname{Ig} \mathrm{T}, \operatorname{IgX}$, and $\operatorname{IgA}$ are generally restricted to mucosal secretions. The discovery of a low molecular weight "J" or "joining" chain as a component of polymeric Igs suggested a potential mechanism for polymerization of individual Ig molecules into higher molecular weight complexes [102-104]. The most primitive extant vertebrates in which the IGJ gene has been identified are the cartilaginous fish, concurrent with the presence of polymeric IgM. Although the IGJ gene has been identified in almost all lineages of jawed vertebrates, it is surprisingly absent in some lineages of Osteichthyes (bony fishes). No ortholog of the IGJ gene has been identified in any species of the class Actinopterygii (ray-finned bony fishes) for which the genome has been sequenced and annotated, including Atlantic cod (Gadus morhua), common carp (Cyprinus carpio), tilapia (Oreochromis niloticus), zebrafish (Danio rerio), medaka (Oryzias latipes), and three-spined stickleback (Gasterosteus aculeatus). In contrast to the rayfinned bony fishes, IGJ genes and functional J chain proteins were recently identified in two species of the class Sarcopterygii (lobe-finned bony fishes, the West Indian Ocean coelacanth (Latimeria chalumnae), and the African lungfish (Protopterus dolloi) [105]). These findings suggest that the $I G J$ gene was lost during the evolution of the Actinopterygii after their divergence from a common ancestor with the Sarcopterygii. Despite the absence of J chain, ray-finned bony fishes are capable of forming polymeric IgM and IgT that can be transported into mucosal secretions [38].

\section{Evolution of Cellular Receptors for Igs}

The unique structure of vertebrate Igs allows for simultaneous binding of antigen via the $\mathrm{N}$-terminal variable regions of the Ig heavy and light chains and execution of effector functions via the C-terminal constant $(\mathrm{Fc})$ region of the Ig heavy chains. Evolution of multiple Ig heavy chain isotypes in higher vertebrates expanded the repertoire of Ig-mediated effector functions, including specialized functions at mucosal surfaces. The simplest effector functions involve neutralization of microbes and their toxic byproducts, whereas killing of microbes can be affected by interaction of Igs with soluble factors found in serum and secretions. The concurrent emergence of Igs and proteins of the classical complement pathway in cartilaginous fishes is the earliest example of a specific immune effector function mediated by the Fc region of Ig heavy chains [106]. As the immune system diversified during vertebrate evolution, cellular receptors for Ig heavy chains (Fc receptors) allowed host cells to bind Igs for the purpose of internalization, transport, and/or activation of intracellular signaling pathways. The most evolutionarily ancient of the vertebrate Fc receptors is the polymeric Ig receptor (pIgR), which first emerged in bony fishes (reviewed in [8]) (Figure 3). The primary function of $\mathrm{pIgR}$ is to transport polymeric Igs (IgM, IgT, IgX, and IgA) across glandular and mucosal epithelial cells into external secretions (see below). The fact that the extracellular Ig-binding region of $\mathrm{pIgR}$ is composed of multiple Ig-like domains suggests that the PIGR 
gene evolved by duplication of a primordial Ig gene is driven by the need for an efficient mechanism for transport of mucosal Igs into external secretions. Similar forces may have driven the evolution of FcRY, a receptor first described for its function of transporting IgY from maternal blood to the embryo yolk sac in chicken [9, 107-109]. FcRY is not structurally homologous to $\mathrm{pIgR}$ or mammalian $\mathrm{Fc}$ receptors but is instead homologous to mammalian receptors for mannose and phospholipase A2, with lectin-like extracellular domains (Figure 3). A BLAST search of the National Center for Biotechnology Information (NCBI) nucleotide database for homologs of the gene encoding chicken FcRY (designated PLA2R1 based on its homology to phospholipase A2 receptor 1) revealed homologous genes in many bird species, as well as turtles, lizards, alligators, and mammals. However, the functional significance of FCRY/PLA2R1 in the transport of IgY in reptiles (and possibly IgG in mammals) has not been explored. A functional equivalent of FcRY in mammals is FcRn, which mediates transport of IgG across endothelial and epithelial cells in such tissues as placenta and mucosal epithelia (reviewed in $[110,111])$. FcRn is homologous in structure to major histocompatibility class (MHC) I molecules, comprising a ligand-binding alpha chain associated with soluble $\beta 2$-microglobulin (Figure 3).

A unique feature of the mammalian immune system is the expression of $\mathrm{Fc}$ receptors for various Ig isotypes by cells of hematopoietic origin (Figure 3) (reviewed in [10]). Engagement of these Fc receptors by Ig (in the presence or absence of bound antigen, depending on the particular Fc receptor) initiates intracellular signaling pathways that can either augment or inhibit immune responses. With the exception of FceRII, which has a single C-type lectinlike domain, the extracellular Ig-binding regions of these hematopoietic Fc receptors comprise 1, 2, or 3 Ig-like domains [10]. Genes encoding Fc $\alpha / \mu \mathrm{R}, \mathrm{Fc} \gamma \mathrm{RI}, \mathrm{Fc} \gamma \mathrm{RIII}, \mathrm{F} c \varepsilon \mathrm{RI}$, and FceRII are widely distributed among mammalian species, whereas genes encoding Fc $\alpha$ RI and Fc $\gamma$ RII are restricted to the primate lineage, suggesting recent evolutionary origins. The genes encoding the $\alpha, \beta$. and/or $\gamma$ chains of FceRI, Fc $\gamma$ RII, and Fc $\gamma$ RIII are linked in a cluster on the long arm of human chromosome 1 (1q23), not far removed from the gene for the $\alpha$ chain of Fc $\gamma$ RI at 1q21. This tight linkage is consistent with duplication and diversification of a primordial FcR gene in a common ancestor of mammals. The primate-specific genes encoding the $\alpha$ and $\beta$ chains of Fc $\gamma$ RII appear to have evolved more recently. Another cluster of immune-related genes on the long arm of chromosome 1 includes the genes for pIgR (1q31) and $\mathrm{Fc} \alpha / \mu \mathrm{R}$ (1q32). Although the overall homology between $\mathrm{pIgR}$ and $\mathrm{Fc} \alpha / \mu \mathrm{R}$ is relatively low, they share a conserved binding site for IgA and IgM in the $\mathrm{N}$-terminal Ig-like domain. Interestingly, the genes encoding FcRn and Fc $\alpha$ RI are closely linked on the long arm of chromosome 19 (19q13.3 and 19q13.42, resp.), although they bear little homology beyond the presence of a single Ig-like domain in the extracellular region. Finally, the gene for the lectin-like receptor FceRII is located in an unrelated locus on the short arm of chromosome 19 (19p13.3).

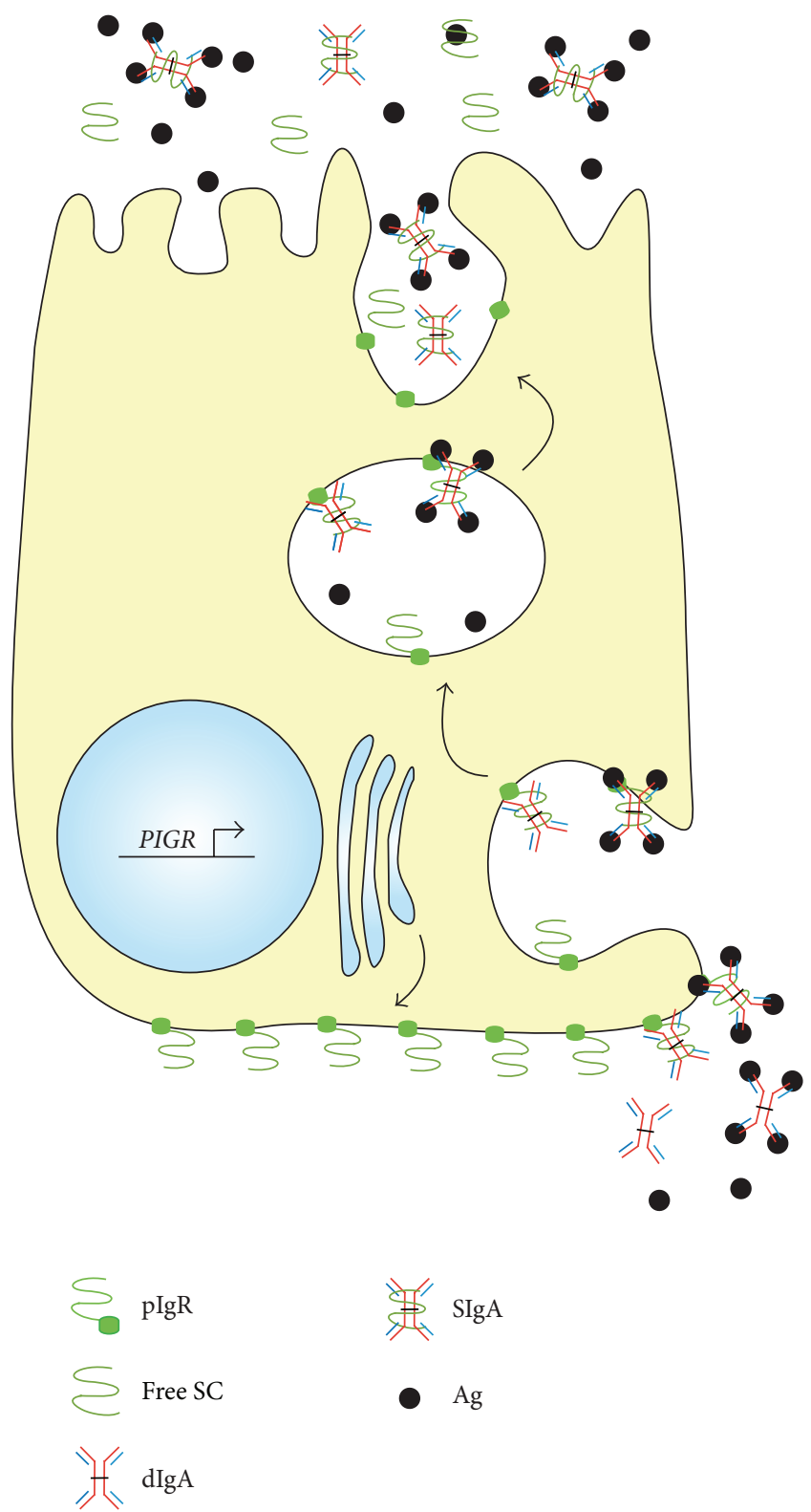

FIGURE 4: Transcytosis of pIgR through a polarized epithelial cell and formation of secretory Igs. A polarized columnar epithelial cell is illustrated, with the apical surface at the top and the basolateral surface at the bottom. Newly synthesized pIgR is targeted to the basolateral surface, where it binds polymeric Ig (pIg; illustrated here as dimeric (d) $\operatorname{Ig} \mathrm{A}$ ) with or without bound antigen (Ag). Following receptor-mediated endocytosis, pIg-bound and unoccupied pIgR molecules are transported through a series of intracellular vesicles to the apical surface. Proteolytic cleavage of pIgR at the extracellular face of the plasma membrane releases free secretory component (SC) and secretory SIg (illustrated here as SIgA). Modified from [13] with permission from John Wiley and sons.

\section{Unique Biological Functions of pIgR}

The pIgR is expressed on the surface of glandular and mucosal epithelial binds, where it binds selectively to polymeric Ig (pIg) and mediates its transport across epithelial cells into external secretions (reviewed in $[17,111,112]$ ). Most of 


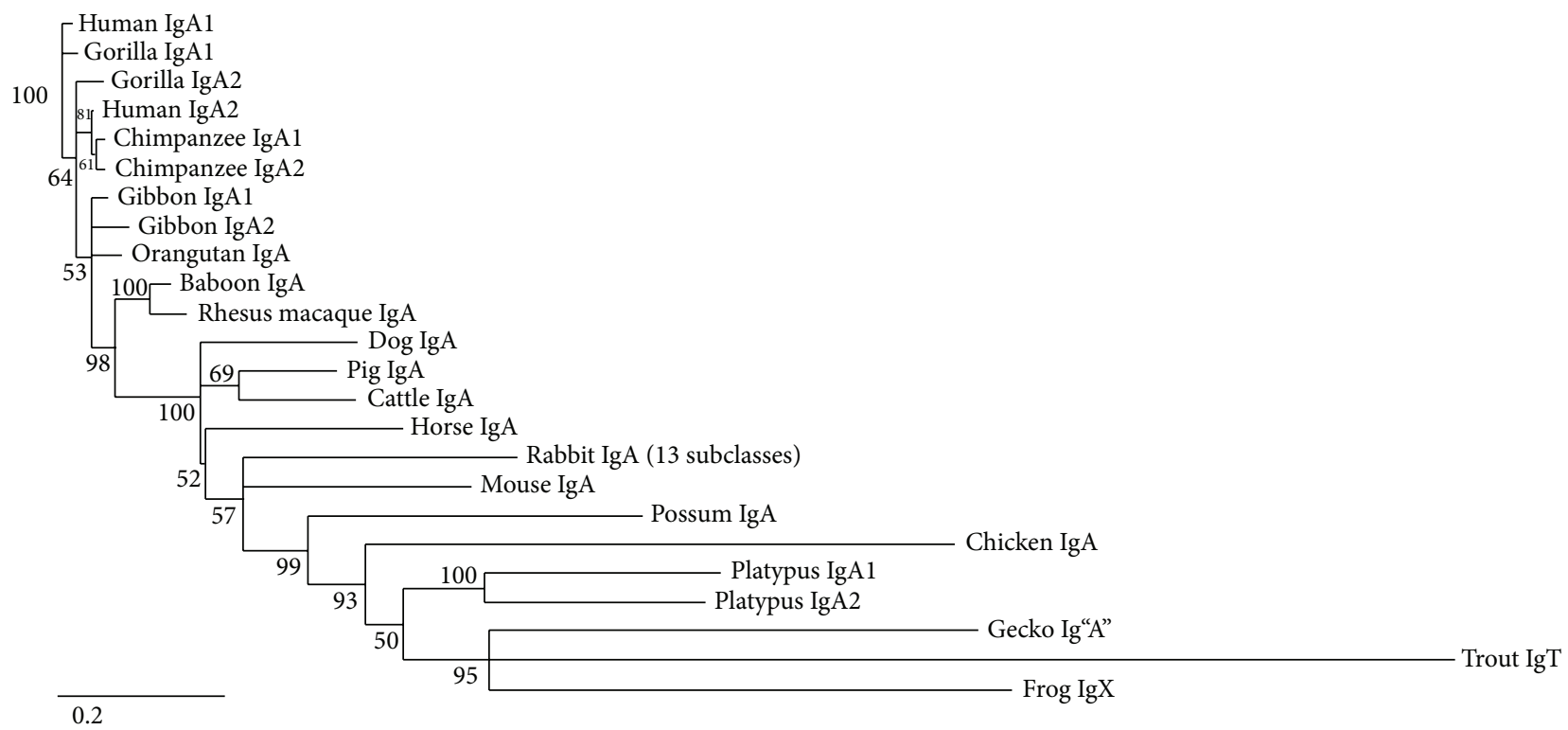

(a)

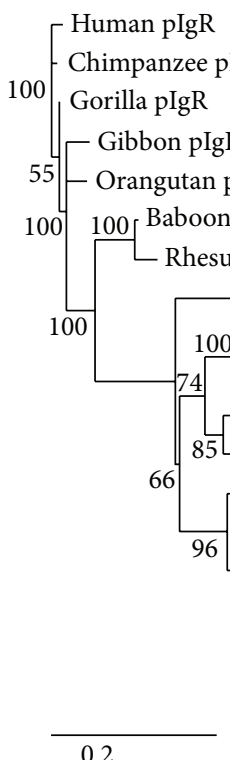

0.2
Rabbit pIgR

Possum pIgR

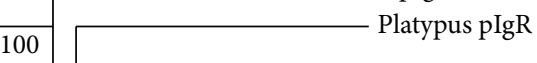

- Mouse pIgR

Pig pIgR

Cattle pIgR

- Horse pIgR
75

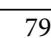

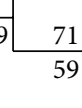
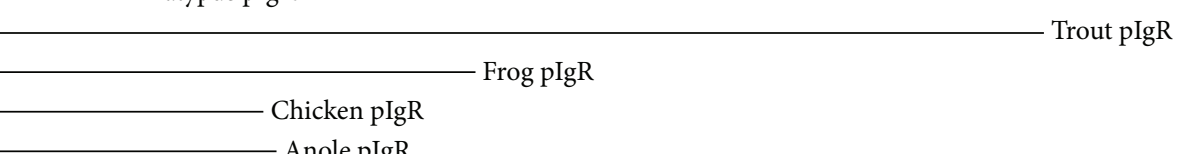

FIgURE 5: Coevolution of mucosal Igs and pIgR. Simplified neighbor-joining phylogenetic trees of vertebrate (a) Ig and (b) pIgR protein sequences, with human IgAl and pIgR denoted as outgroups. Horizontal distances are proportional to the degree of divergence following a multiple alignment of amino acid sequences. Numbers at nodes denote bootstrap support for each bifurcation after 100 replications. Accession numbers for mucosal Ig sequences: human (Homo sapiens) IgA1, J00220; IgA2 (allotype m1), J00221; gorilla (Gorilla gorilla) IgA1, X53703; IgA2, X53707; chimpanzee (Pan troglodytes) IgA1, X53702; IgA2, X53706; gibbon (Hylobates lar) IgA1, X53708; IgA2, X53709; Bornean orangutan (Pongo pygmaeus) IgA, X53704; baboon (Papio anubis) IgA, DQ868435; rhesus macaque (Macaca mulatta) AY039245; pig (Sus scrofa) IgA, U12594; cattle (Bos taurus) IgA, AF109167; dog (Canis lupus familiaris) IgA, L36871; horse (Equus caballus) IgA, AY247966; mouse (Mus musculus) IgA, D11468; rabbit (Oryctolagus cuniculus) IgA1, X51647; brushtail possum (Trichosurus vulpecula) IgA, AF027382; duck-billed platypus (Ornithorhynchus anatinus) IgA1, AY055778; IgA2, AY055779; chicken (Gallus gallus) IgA, AAB22614.2; leopard gecko (Eublepharis macularius) Ig"A" (so designated because of its uncertain phylogeny with homology to both IgA and IgY), ABG72684.1; African clawed frog (Xenopus laevis) IgX, S03186; rainbow trout (Oncorhynchus mykiss) IgT, AAW66981.1. Accession numbers for pIgR sequences, with species that vary from those used for the mucosal Ig alignment in panel A noted in parentheses: human, NM_002644; chimpanzee, XM_003308710; gorilla, XM_004028295; gibbon, XM_003272974; Sumatran orangutan (Pongo abelii), NM_001131626; baboon, XM_003893189; rhesus macaque, XM_001083307; pig, NM_214159; cattle, NM_174143; dog, XM_537133; horse, XM_001492298; mouse, NM_011082; rabbit, NM_001171045; brushtail possum, AF091137; duck-billed platypus, XM_001508602; chicken, NM_001044644; green anole (Anolis carolinensis), XM_003224013; African clawed frog, EF079076; rainbow trout, FJ940682. 
our knowledge of pIgR-mediated transcytosis of mucosal Igs is derived from studies of mammalian secretory IgA (SIgA), as illustrated in Figure 4. Transcription of the PIGR gene and translation of pIgR mRNA is accompanied by insertion of the nascent protein into the endoplasmic reticulum. The pIgR undergoes substantial glycosylation during transport through the ER and Golgi apparatus and is then targeted to the basolateral surface of polarized epithelial cells. Membrane-bound pIgR binds pIg and pIg-containing immune complexes, which are internalized along with unoccupied pIgR via receptor-mediated endocytosis and then transcytosed through a series of intracellular vesicles to the apical surface. During transcytosis, intracellular pIg antibodies can neutralize bacteria, viruses, and other antigens that have gained access to the interior of the epithelial cell. At the apical surface, proteolytic cleavage of the membranespanning region of pIgR leads to the release of its extracellular domain, known as secretory component (SC), either in free form or covalently bound to pIg. Secretory Igs can neutralize pathogens and antigens within the mucosal lumen and facilitate excretion of antigens that were transported through the epithelial cell as IgA immune complexes. The SC moiety of SIgA has been shown to protect IgA from degradation by host and bacterial proteases and, along with free SC, confers additional innate immune functions that protect the epithelial surface from microbial invasion and limit potentially damaging host inflammatory responses (reviewed in [113]). The finding of an SC-like polypeptide associated with polymeric $\operatorname{IgT}$ in rainbow trout [38], polymeric $\operatorname{IgX}$ in Xenopus [50], and polymeric IgA in birds [114] suggests that all vertebrate pIgRs share the function of transporting polymeric Igs into external secretions. In many mammalian species, pIgR mediates epithelial transcytosis of both polymeric IgM and IgA (reviewed in [111]). Although direct evidence is not yet available, it is reasonable to assume that pIgR transports IgM in lower vertebrates. It will be interesting to investigate whether the SC moiety of secretory Igs in lower vertebrates mediates additional innate immune functions, as has been demonstrated for mammalian SC.

\section{Coevolution of pIgR and Mucosal Igs}

Molecular cloning of the PIGR gene was first reported for mammalian species, including eutherians, marsupials, and monotremes [115-127]. Subsequent elucidation of PIGR sequences from diverse species of jawed vertebrates has allowed a comprehensive analysis of the evolutionary origins of the PIGR gene [38, 128, 128-132] and additional sequences available in the Genbank database. Whereas no ortholog of the PIGR gene has been found in any species of cartilaginous fish, the PIGR gene has been annotated in all species of teleost fish for which the genome has been sequenced. No ortholog of the PIGR gene has been reported in lobe-finned bony fishes, but further analyses of whole genome sequences will be required to determine whether the PIGR gene was lost following the split of the Sarcopterygii. It thus appears that the PIGR gene emerged in a common ancestor of higher vertebrates, after the split of cartilaginous fish and prior to the evolution of modern teleosts, likely driven by the selective pressure to provide a mechanism for transport of polymeric Igs such as IgM and IgT into mucosal secretions. This hypothesis is supported by a comparison of phylogenetic trees based on amino acid sequences for IgT, IgX, and IgA heavy chains and pIgR (Figure 5). The predicted evolutionary distance between trout IgT and frog $\operatorname{IgX}$ is similar to the distance between trout and frog pIgR, suggesting that the transition from $\operatorname{IgT}$ to $\operatorname{IgX}$ as the dominant mucosal Ig isotype was accompanied by adaptations in pIgR structure. Similar parallels can be seen in the transition from $\operatorname{IgX}$ to $\operatorname{IgA}$ in reptiles, birds, and mammals and the concurrent evolution of pIgR.

Alignments of the amino acid sequences of mucosal Ig heavy chains and $\mathrm{pIgR}$ from 10 representative vertebrate species provide further support for the theory of coevolution of mucosal IGH and PIGR genes (Figure 6). A common feature of Ig and pIgR proteins is the presence of repeating Ig-like domains (see Figure 2 for the basic structure of these domains). The structure of IgT, IgX, and IgA heavy chains from fish, amphibians, reptiles, and birds is similar to that of IgM, with 4 constant Ig-like domains. In mammalian IgA (and IgG), the exon for the 2nd constant region was truncated to encode a short "hinge" region, which confers greater mobility to the antigen-binding region at the $\mathrm{N}$ terminus. Thus, the $\mathrm{C}_{\mathrm{H}} 3$ domain of $\operatorname{IgT}$, IgX, and $\operatorname{IgA}$ in lower vertebrates is structurally and functionally homologous to the $\mathrm{C}_{\mathrm{H}} 2$ domain of mammalian IgA. The heavy chains of $\operatorname{IgT}, \operatorname{IgX}$, and $\operatorname{IgA}$ have retained a characteristic feature of the IgM heavy chain, that is, the presence of a conserved cysteine residue in the tailpiece that allows disulfide bonding between heavy chains of individual Ig proteins to form higher molecular weight polymers. These large Ig structures containing multiple antigen-binding sites are particularly well suited for immune clearance of large antigens found at mucosal surfaces, such as intact microbes and food particles. In mucosal Igs from most vertebrate orders, the J chain protein initiates this polymerization process by disulfide bonding with 2 Ig heavy chains, remaining associated with the polymeric Ig at a stoichiometric ratio of $1 \mathrm{~J}$ chain subunit per 2, 3, 4, or 5 Ig units. Despite the absence of J chain, the predominant form of IgM and IgT in mucus secretions in rainbow trout was found to be polymeric, in contrast to monomeric forms of IgM and IgT in the blood [38]. In mammals, IgM is mainly found as a pentamer, whereas the shorter heavy chain of mammalian IgA restricts its polymeric forms to dimers, trimers, and tetramers. Further studies will be required to characterize the polymeric structures of IgM, $\operatorname{IgT}$, IgX, and IgA in lower vertebrates.

Alignment of pIgR amino acid sequences from 10 representative vertebrate species reveals structural changes that were evolved in parallel with structural changes in mucosal Igs (Figure 6(b)). All pIgR proteins have an N-terminal hydrophobic leader peptide, required for targeting of the nascent protein into the ER. The extracellular region of pIgR protein is characterized by repeating "Ig-like" domains, similar to Ig heavy chains $[115,133]$. Interestingly, the number of extracellular Ig-like domains has increased during vertebrate evolution, culminating with a total of 5 domains 


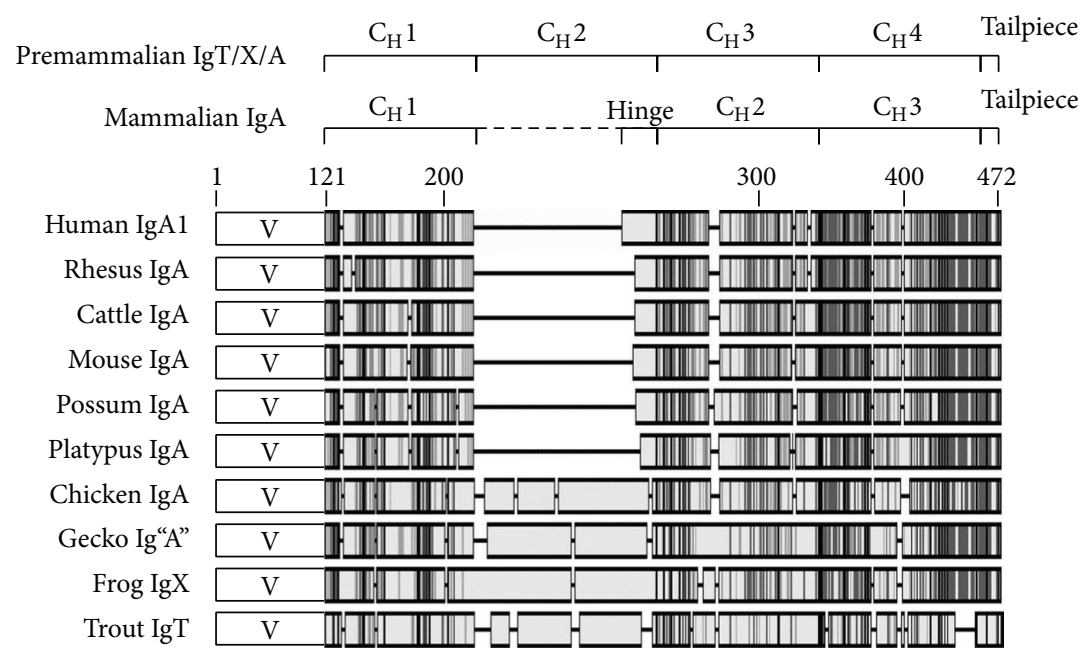

(a)

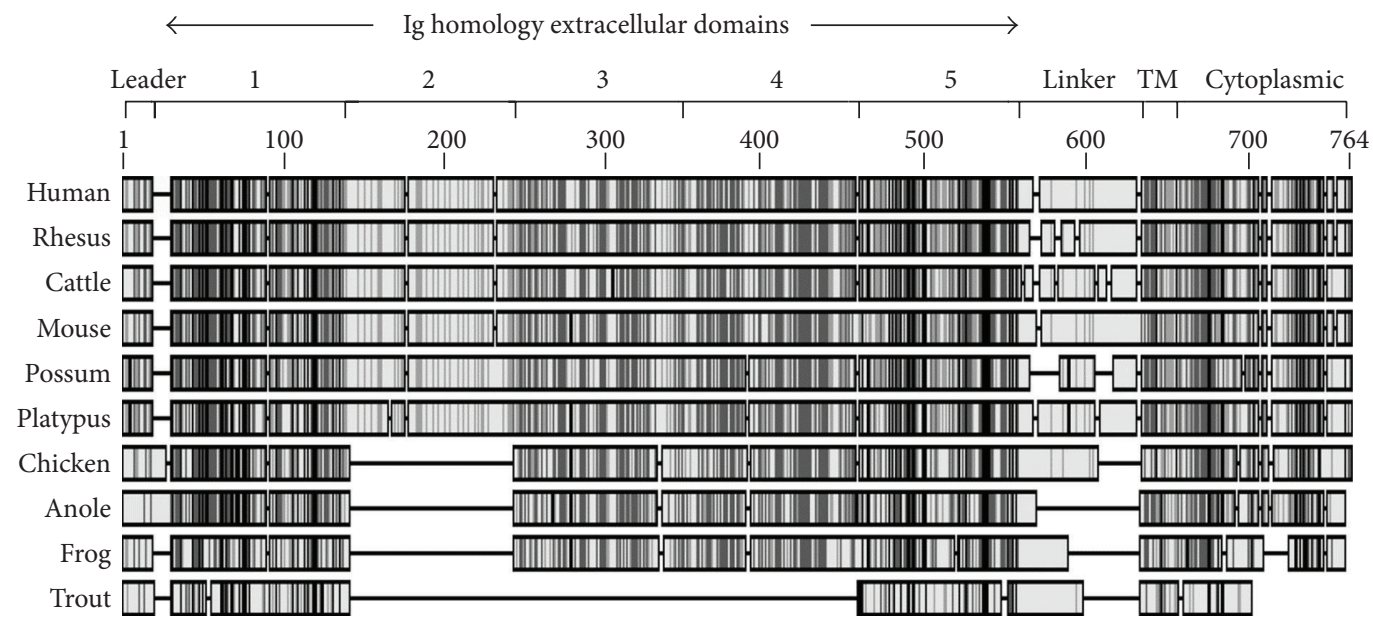

(b)

FIGURE 6: Interspecies similarity in mucosal Ig and pIgR protein sequences from 10 representative vertebrate species. Alignments in amino acid sequences correspond to the phylogenetic trees shown in Figure 5. (a) Numbering of mucosal Ig amino acids corresponds to the sequence of human IgAl, beginning with the first residue of the variable domain. $\mathrm{C}_{\mathrm{H}}$ : heavy chain constant region domain. (b) Numbering of pIgR amino acids corresponds to the sequence of human pIgR, beginning with the first residue of the leader peptide. TM: transmembrane. For both alignments, the intensity of shading at each position signifies the degree of similarity among mucosal Ig or pIgR sequences from different species. Gaps in sequence alignments signify regions of limited interspecies homology. Approximate boundaries are noted of key structural elements in mucosal Ig and pIgR proteins.

in mammalian pIgR. By contrast, pIgR from amphibians, reptiles, and birds contains 4 extracellular domains, lacking a homolog of domain 2 of mammalian pIgR. The most primitive form of pIgR found in teleost fish contains only 2 extracellular domains, homologous to domains 1 and 5 of mammalian pIgR. Interspecies homology is greatest in domain 1, which has been shown to be critical for binding of mammalian pIgR to polymeric Igs (reviewed in [111]). Highly conserved internal disulfide bonds are found in all the Iglike domains of pIgR, characteristic of the immunoglobulin fold. An additional disulfide bond is found in domain 5 of pIgR from mammals, birds, reptiles, and amphibians, but not fish. In human SIgA, this "extra" disulfide bond in domain 5 has been shown to rearrange to form a disulfide bond with cysteine residues in one of the heavy chains of polymeric IgA [134]. Although the structure of SIgA has not been fully characterized for lower vertebrates, it is reasonable to assume that similar disulfide bonds form between domain 5 of pIgR and polymeric IgA or IgX from birds, reptiles, and amphibians. The linker region connecting domain 5 of $\mathrm{pIgR}$ to the transmembrane domain has a random structure that is poorly conserved across species. Proteolytic cleavage of pIgR within this domain leads to the release of SC from the apical surface of epithelial cells, either free or bound to polymeric Ig. The cytoplasmic domain of mammalian pIgR contains a number of intracellular sorting motifs that interact with cytoplasmic proteins to direct pIgR through the transcytotic pathway (reviewed in [111]). These motifs are reasonably 


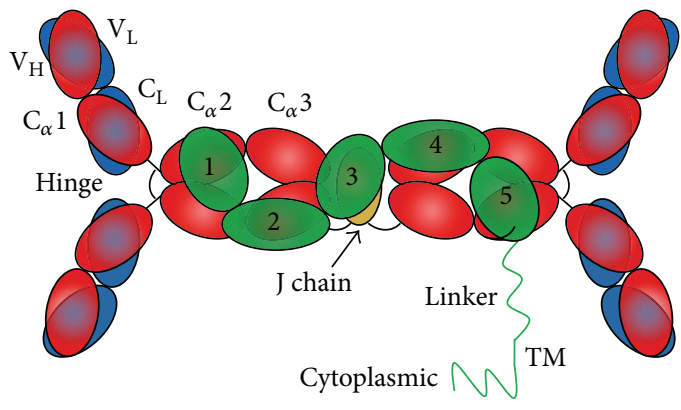

(a)

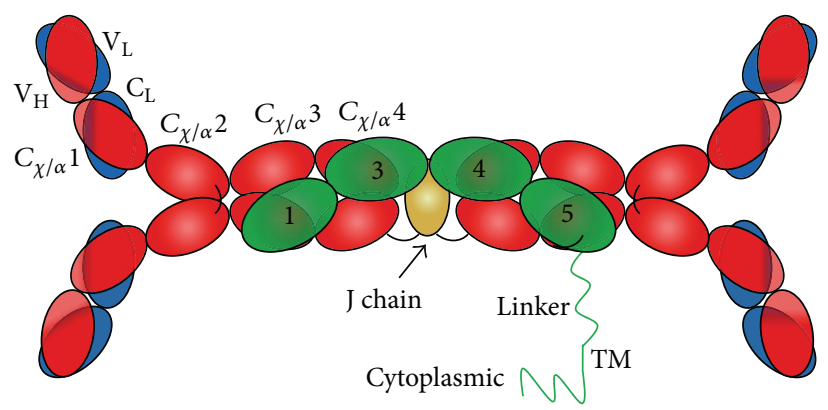

(b)

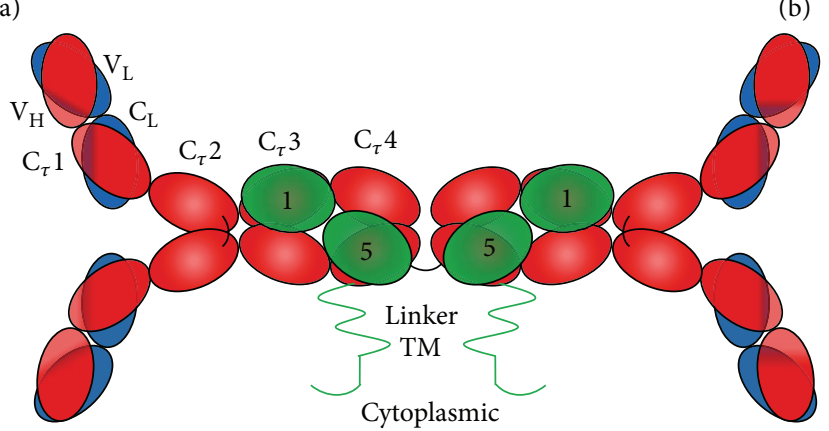

(c)
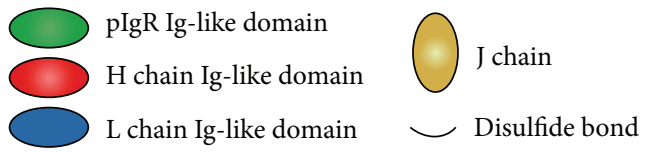

FIgURE 7: Theoretical model for changes in the structure of secretory Igs during evolution. (a) The structure for mammalian SIgA is adapted from the model of Woof and Russell [16] for human SIgA1, with permission from Nature Publishing Group. (b) and (c): Theoretical models for the structure of IgX/A from amphibians and birds and SIgT from teleost fish, respectively, are predicted from alignment of Ig heavy chain and $\mathrm{pIgR}$ sequences with mammalian homologs.

well conserved in pIgR from birds and reptiles, but not in pIgR from amphibians and fish, suggesting that complex mechanisms of intracellular trafficking of pIgR coevolved with the increasing complexity of the mucosal immune system.

\section{Hypothetical Models for Changes in Secretory Ig Structure during Coevolution of Mucosal Igs and pIgR}

A large number of structural and functional analyses over the past 30 years allowed the development of detailed models for the structure of mammalian SIgA (reviewed in [111, 135]) (Figure 7(a)). Domains 1 and 5 of pIgR, the most highly conserved Ig-like domains, associate with the $\mathrm{C} \alpha 2$ subunits of two adjacent IgA heavy chains in a near-planar structure [136, 137]. During transcytosis, a disulfide bond forms between highly conserved cysteine residues in domain 5 of pIgR and the $\mathrm{C} \alpha 2$ domain of one of the IgA heavy chains [134]. Domains 2, 3, and 4 allow mammalian pIgR to assume a flexible extended structure, which is thought to wrap around the IgA heavy chains and protect against degradation from host and microbial proteases. Binding of mammalian pIgR to polymeric IgA or IgM requires the presence of $J$ chain connecting the Ig subunits (reviewed in [138]), and J chaindeficient mice fail to transport IgA and IgM into external secretions [139-141]. Structure-function studies using mutant forms of human J chain suggested that J chain binds directly to $\mathrm{pIgR}$ and also maintains polymeric Ig in an optimal conformation for pIgR binding and transcytosis [142]. The unstructured linker region connecting domain 5 of pIgR to the transmembrane (TM) region gives membrane-bound pIgR the flexibility to bind large polymeric Igs (with or without associated antigens) and provides an exposed site for proteolytic cleavage of $\mathrm{pIgR}$ to SC. The C-terminal region of pIgR extends past the cytoplasmic face of the plasma membrane, allowing association with cytoplasmic factors that regulate trafficking of $\mathrm{pIgR}$ with or without bound polymeric Ig.

Although detailed structural studies have not yet been performed on secretory Igs from lower vertebrates, hypothetical models can be constructed based on alignments with their mammalian homologs. A model for secretory $\mathrm{IgX} / \mathrm{A}$ in birds, reptiles, and amphibians is illustrated in Figure 7(b), showing the $\mathrm{C}_{\chi / \alpha} 2$ domain in place of the hinge region of mammalian IgA. The numbering of the extracellular domains of pIgR corresponds to the homologous domains in mammalian pIgR, noting the absence of domain 2. In 
this model, the $\mathrm{C}_{\chi / \alpha} 3$ domains of two adjacent IgX/A heavy chains (homologous to the $\mathrm{C}_{\alpha} 2$ domain of mammalian IgA) bind to the highly conserved domains 1 and 5 of pIgR. Given the conservation of the analogous cysteine residues in domain 5 of $\mathrm{pIgR}$ and the $\mathrm{C}_{\chi / \alpha} 3$ domain of $\mathrm{IgX} / \mathrm{A}$, it is assumed that a disulfide bond forms between pIgR and polymeric Ig during epithelial transcytosis in birds, reptiles, and amphibians. The absence of domain 2 in pIgR from these vertebrate orders necessitates a more rigid structure than that of mammalian pIgR, with a corresponding decrease in its ability to wrap around the IgX/A heavy chains and provide protection against proteoltyic degradation. Despite the shorter length of pIgR in birds, reptiles, and amphibians, the association with the J chain subunit of polymeric IgX/A still appears to be required. Recombinant pIgR from the African frog (Xenopus laevis) was shown to bind with moderately high affinity to human polymeric IgA containing J chain, but not to monomeric IgA [125]. The affinity of Xenopus pIgR for human pIgA was improved when Xenopus J chain was substituted for human J chain in a chimeric polymeric IgA molecule. The lack of sequence conservation across species in the linker region connecting domain 5 of pIgR to the TM region suggests that it acts as a nonspecific "spacer." As stated above, the cytoplasmic region of pIgR appears to have evolved over time to provide enhanced regulation of pIgR trafficking.

The hypothetical structure of secretory IgT from teleost fish in Figure 7(c) illustrates how the most primitive form of pIgR comprising only extracellular domains 1 and 5 could associate with polymeric Ig and mediate epithelial transcytosis. Association of pIgR domain 1 with the $\mathrm{C}_{\tau} 3$ domain of IgT would preserve the functional homology with secretory Igs in higher vertebrates. The short length of teleost pIgR would necessitate the association of domain 5 with a $\mathrm{C}_{\tau} 3$ domain on one of the heavy chains of the same IgT, rather than spanning across to the adjaent IgT subunit. While this model preserves the highly conserved association of $\mathrm{pIgR}$ domain 1 with the orthologous domain of the IgT heavy chain, it does not explain the selectivity of teleost pIgR for polymeric rather than monomeric IgT. Although there is no experimental evidence to support this model, it could be hypothesized that dimerization of two pIgR molecules in the plasma membrane is required for high affinity binding of IgT, as illustrated in the model in Figure 7(c). This hypothetical model would also explain the lack of a necessity for J chain in polymeric IgT, since each subunit in the pIgR dimer would only be in contact with one IgT subunit. The unstructured linker region connecting domain 5 of pIgR to the TM region would provide flexibility for association of 2 membranebound pIgR molecules with a large polymeric IgT molecule.

Taken together, the structural models for secretory Igs shown in Figure 7 are consistent with the selection of a more functional pIgR molecule over evolutionary time. Duplication and diversification of the extracellular Ig-like domains of pIgR would provide a longer, more flexible surface for binding to polymeric Igs with higher affinity and protecting the Ig heavy chains against proteolytic attack. Expansion of the cytoplasmic domain of pIgR and incorporation of motifs for binding cytoplasmic proteins would allow regulated trafficking of pIgR and polymeric Igs across mucosal and glandular epithelial cells. Importantly, these models illustrate a potential path for coevolution of $I G H$ and PIGR genes, driven by the common selective pressure to provide antigenspecific humoral immune responses at mucosal surfaces.

\section{Evidence that the Commensal Microbiota Provided the Driving Force for Coevolution of Mucosal Igs and pIgR}

From the earliest evolution of vertebrate animals, mucosal Igs have been an integral part of the emerging adaptive immune system. Clearly, many environmental factors served as driving forces for the evolution of the adaptive immune system in vertebrates, including a longer lifespan than many (but not all) invertebrates and a more diverse diet that could introduce a broader range of potential gut pathogens. However, it has been proposed that the most significant force may have been the dramatic increase in the numbers and complexity of the resident microbiota in the evolution of vertebrates from their invertebrate ancestors [1, 143, 144]. Antibodies in mucosal secretions contribute to immune homeostasis by limiting access of microbes and their products to the body proper, maintaining the integrity of the epithelial barrier and shaping the composition of the commensal microbiota in favor of metabolically beneficial microorganisms [145]. The predominance of polymeric Igs in these secretions promotes these functions by providing multiple antigen-binding sites per Ig complex, thus increasing the overall avidity of antigenantibody interactions. Structural and functional refinements in mucosal Igs, culminating with the multifunctional secretory IgA molecule in mammals, have further enhanced their ability to enhance immune homeostasis.

The early emergence of $\mathrm{pIgR}$ in vertebrate evolution provided a mechanism for efficient transport of mucosal Igs into external secretions. It is well documented that crosstalk between mucosal epithelial cells and the resident microbiota modulates expression of pIgR (reviewed in [17, 111, 112]), and it is reasonable to assume that these host-microbe interactions provided a driving force for evolution of the PIGR gene in vertebrates. The first demonstration that gut bacteria may modulate pIgR expression in epithelial cells was the finding that butyrate, a bacterial fermentation product and important energy source in the colon, upregulated expression of $\mathrm{pIgR}$ in the human colonic epithelial cell line HT-29 [146]. A role for commensal bacteria in $\mathrm{pIgR}$ regulation was subsequently demonstrated by the observation that $\mathrm{pIgR}$ expression was increased when germ-free mice were colonized with Bacterioides thetaiotaomicron, a prominent organism of the normal mouse and human intestinal microbiota [147]. A more recent study, using a model of reversible colonization of germfree mice with a nondividing mutant of Escherichia coli, demonstrated that a long-lived SIgA response could be sustained that specifically recognized the inducing bacteria [148]. However, exposure of E. coli-colonized mice to other bacteria limited the duration of the SIgA response against the original colonizer, suggesting a dynamic equilibrium between members of the gut microbial community and host SIgA. A 
study from the laboratory of Finn-Eirik Johansen demonstrated that diversity of the bacterial community in the cecal lumen was reduced in pIgR-knockout mice, supporting a role for SIgA in limiting overgrowth of selected species [149]. In contrast, the community of bacteria adherent to the epithelial surface was more diverse in pIgR-knockout mice than in wild-type mice, and these adherent bacteria caused enhanced expression of several epithelial antimicrobial peptides. These findings suggest that bacteria-specific SIgA anchored in the mucus layer restricts adhesion of bacteria to the epithelial surface and limits bacterial stimulation of host epithelial cells. A recent study from the author's laboratory, employing a breeding scheme in which $\mathrm{Pigr}^{-/-}$dams were bred to $\mathrm{Pigr}^{+/-}$ males and vice versa, demonstrated that SIgA antibodies in breast milk promote long-term intestinal homeostasis by regulating the gut microbiota and gene expression in colonic epithelial cells [150].

A direct role for commensal and/or pathogenic bacteria in the regulation of $\mathrm{pIgR}$ expression suggests that the innate immune system may "prime" epithelial cells for transport of polymeric Ig produced during the adaptive immune response. Host cells mediate innate immune responses to microbial components through toll-like receptor (TLR) signaling (reviewed in $[151,152]$ ). Intestinal epithelial cells have been shown to express a wide variety of TLRs, the expression of which is upregulated during intestinal inflammation [153155]. Significantly, expression of pIgR was shown to be upregulated in the HT-29 human intestinal epithelial cell line by bacterial LPS, a ligand for TLR4 [156, 157]. Similar induction of PIGR gene transcription was seen following direct binding of bacteria of the family Enterobacteriaceae, which express a form of LPS that stimulates TLR4 [158]. A recent study from the author's laboratory demonstrated that shRNA-mediated knockdown of myeloid differentiation primary response protein 88 (MyD88), a cytoplasmic adapter protein that transduces signals from cell surface TLR4, blocked the induction of PIGR gene transcription by LPS in HT-29 cells [159]. The in vivo significance was confirmed by the finding that mice with a targeted deletion of the Myd88 gene only in intestinal epithelial cells had reduced expression of pIgR compared to wild-type littermates [159]. Mice with targeted depletion of MyD88 in intestinal epithelial cells also exhibited reduced expression of mucin-2, the major component of the intestinal mucus layer, and several antimicrobial peptides and decreased transmucosal electrical resistance. These alterations in epithelial barrier function were accompanied by significant changes in the composition of the fecal microbiota, increased numbers of bacteria adherent to the intestinal mucus layer, and a dramatic increase in translocation of gut bacteria into the draining mesenteric lymph nodes, including the opportunistic pathogen Klebsiella pneumoniae. These findings demonstrate that MyD88-mediated crosstalk between the gut microbiota and intestinal epithelial cells is crucial for optimal expression of pIgR, production of SIgA, development of a healthy gut microbiota, and maintenance of intestinal homeostasis.

A model can be proposed in which continuous stimulation of intestinal epithelial cells by gut bacteria regulates
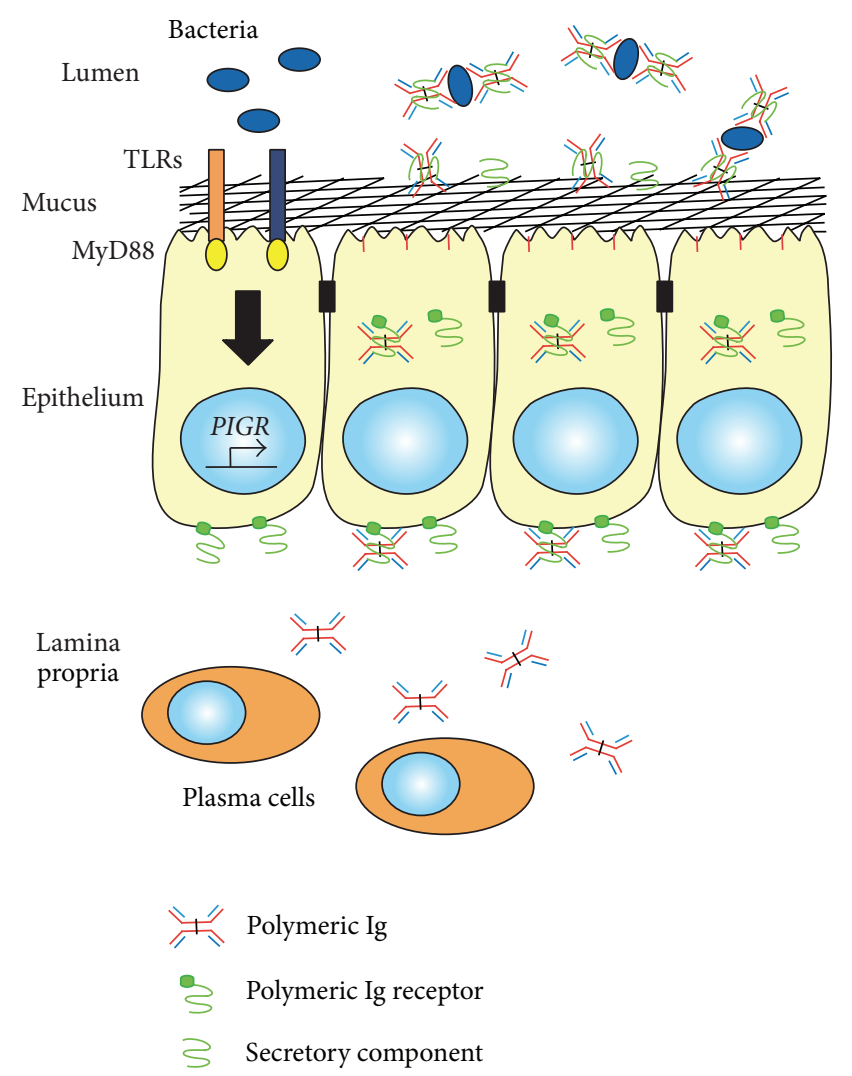

FIGURE 8: Crosstalk between the polymeric immunoglobulin receptor, secretory immunoglobulins, and the gut microbiota. The singlelayered epithelium that lines the gastrointestinal tract is covered with a thick mucus layer, which physically excludes members of the resident microbiota but allows diffusion of shed components of microbial cells. Stimulation of epithelial toll-like receptors (TLRs) with microbial products engages the cytoplasmic adaptor protein MyD88 and initiates NF $\kappa$ B-dependent signaling pathways. Translocation of activated $\mathrm{NF} \kappa \mathrm{B}$ and other transcription factors to the nucleus enhances transcription of the PIGR gene. Activation of TLRs may also stimulate pIgR transcytosis. Polymeric Igs secreted by lamina propria plasma cells bind to pIgR on the basolateral surface of epithelial cells and are transcytosed to the apical surface along with unoccupied pIgR. Proteolytic cleavage of $\mathrm{pIgR}$ at the apical surface releases secretory SIg and free secretory component (SC). Binding of SIg and SC to luminal bacteria promotes association with the mucus layer and prevents direct access of bacteria to the epithelial surface. Over time, the continuous crosstalk with SIg shapes the composition of the gut microbiota. Modified from [17] under terms of author's copyright with Nature Publishing Group.

pIgR expression and transport of SIgA and promotes immune exclusion of resident and pathogenic bacteria (Figure 8). A dense layer of mucus, which increases in thickness from the proximal to the distal colon, serves to separate bacteria from direct contact with the epithelial surface. Secretion of microbial-associated molecular patterns (MAMPs) by commensal bacteria stimulates MyD88-dependent TLR signaling, leading to enhanced expression of $\mathrm{PIgR}$ and antimicrobial peptides and increased mucus production. Binding of $\mathrm{pIgA}$ to $\mathrm{pIgR}$ and possibly also signaling via MAMPs 
enhances transcytosis of pIgA, pIgA-containing immune complexes, and unoccupied $\mathrm{pIgR}$, which promotes clearance of antigens and pathogens from the lamina propria, intracellular neutralization, and release of SIgA and SC at the luminal surface. SIgA and SC serve to trap bacteria in the mucus layer, limiting their access to the epithelial surface. In mice with a targeted deletion of the Muc2 gene, which have a severely depleted mucus layer in the colon, SIgA, and SC fail to associate with the surface of colonic epithelial cells [160]. The presence of SIgA in the intestinal lumen, whether derived passively from maternal milk or actively via epithelial transcytosis, shapes the composition of the gut microbiota and modulates intestinal epithelial gene expression.

\section{Concluding Remarks}

The first microbes that emerged on Earth almost 4 billion years ago encountered a hostile world where nutrients were scarce, hazards were everywhere, and life was short. With the evolution of multicellular organisms about 3 billion years later, a select group of microbes chose to sacrifice an independent existence for the benefits of a mutualistic relationship with eukaryotic hosts. Prokaryotic-eukaryotic mutualism reached its apex some 500 million years ago with the emergence of primitive vertebrates, whose gastrointestinal tracts were populated by an abundant and diverse commensal microbiota. In humans, the large intestine is home to some 100 trillion microorganisms, 10 times more than the total number of eukaryotic cells in the entire body. The microbes that inhabit the vertebrate GI tract provide many benefits to the eukaryotic host, including digestion of complex food molecules, synthesis of vitamins, and production of soluble factors that enhance the development of the host immune system. In return, the eukaryotic host provides the microbes with a warm, moist place to live, abundant food, low oxygen tension, and a soft bed of mucus on which to form biofilms. When this mutually beneficial arrangement is challenged by pathogenic microbes, the eukaryotic host and the commensal microbiota join forces to battle the pathogens and protect the body from invasion. The vertebrate immune system is equipped with a well-trained army of immune cells and a sophisticated arsenal of weapons (cell surface molecules and secreted factors) that protect the host from all but the most virulent pathogens. This immune "army" also serves as a constant reminder to the commensal microbes that, while they are free to enjoy the amenities of the mucosal surfaces, they are not welcome in the body proper. The emergence of antigen-specific Igs and T-cell receptors in jawed vertebrates began a process of immunological diversification that led to the development of a specialized mucosal immune system in higher vertebrates, in which secretory Igs play a central role. The relationship between host and microbiota is clearly reciprocal; the mucosal Igs that evolved in response to selective pressure from the commensal microbiota play a central role throughout life in shaping the composition, genetics, and metabolic activity of the microbiota $[1,161,162]$.

The epithelial layer lining mucosal surfaces provides a physical and innate immune barrier against penetration of the body proper by microbes, undigested food antigens, and potentially noxious environmental substances. The evolutionary challenge of transporting mucosal Igs into external secretions without compromising the epithelial barrier was met by the emergence of the PIGR gene in an ancestor of bony fishes, encoding an epithelial-specific transmembrane protein that actively transports polymeric Igs across mucosal and glandular epithelia (Figure 4). Structural similarities between Igs and the extracellular Ig-binding domains of pIgR (Figure 6) suggest that duplication and diversification of a gene encoding primordial Ig-like domain may have given rise to the PIGR gene in a primitive vertebrate ancestor. Parallel refinement of the structures of mucosal Igs and pIgR during tetrapod evolution (Figures 6 and 7) culminated in the evolution of the multifunctional SIgA molecule in mammals, in which the pIgR-derived SC subunit provides innate immune functions and protects the antigen-binding IgA polymer from proteolytic degradation. In addition to acting as a powerful force during vertebrate evolution, the reciprocal relationship between $\mathrm{pIgR}$, mucosal Igs, and the commensal microbiota provides benefits throughout the life of the individual. Microbial colonization of newborn vertebrates stimulates development of mucosal B cells and class switching to mucosal Ig isotypes [1, 163]. Microbial factors upregulate expression of pIgR, enhancing transport of mucosal Igs into external secretions, where they in turn regulate the microbiota. This beautifully orchestrated process allows us to maintain a healthy relationship with our resident microbiota, while providing mutual protection against pathogens.

\section{Conflict of Interests}

The author declares that there is no conflict of interests regarding the publication of this paper.

\section{Acknowledgments}

This work was supported by Grant no. AI069027 from the National Institutes of Health of the United States of America (and an associated American Recovery and Reinvestment Act supplement) and a Senior Research Award from the Crohn's and Colitis Foundation of America.

\section{References}

[1] C. L. Maynard, C. O. Elson, R. D. Hatton, and C. T. Weaver, "Reciprocal interactions of the intestinal microbiota and immune system," Nature, vol. 489, no. 7415, pp. 231-241, 2012.

[2] M. F. Flajnik and M. Kasahara, "Origin and evolution of the adaptive immune system: genetic events and selective pressures," Nature Reviews Genetics, vol. 11, no. 1, pp. 47-59, 2010.

[3] M. F. Flajnik and L. du Pasquier, "Evolution of the immune system," in Fundamental Immunology, W. E. Paul, Ed., chapter 4, pp. 67-128, Lippincott Williams \& Wilkins, Philadelphia, Pa, USA, 2012.

[4] M. Hirano, S. Das, P. Guo, and M. D. Cooper, "The evolution of adaptive immunity in vertebrates," Advances in Immunology, vol. 109, pp. 125-157, 2011. 
[5] T. Boehm, N. McCurley, Y. Sutoh, M. Schorpp, M. Kasahara, and M. D. Cooper, "VLR-based adaptive immunity," Annual Review of Immunology, vol. 30, pp. 203-220, 2012.

[6] T. Hunkapiller and L. Hood, "Immunology: the growing immunoglobulin gene superfamily," Nature, vol. 323, no. 6083, pp. 15$16,1986$.

[7] P. Bork, L. Holm, and C. Sander, "The immunoglobulin fold structural classification, sequence patterns and common core," Journal of Molecular Biology, vol. 242, no. 4, pp. 309-320, 1994.

[8] C. S. Kaetzel and M. W. Russell, "Phylogeny and comparative physiology of IgA," in Mucosal Immunology, J. Mestecky, W. Strober, H. Cheroutre, B. Kelsall, B. N. Lambrecht, and M. W. Russell, Eds., chapter 19, Academic Press/Elsevier, Waltham, Mass, USA, 2014.

[9] Y. He and P. J. Bjorkman, "Structure of FcRY, an avian immunoglobulin receptor related to mammalian mannose receptors, and its complex with IgY," Proceedings of the National Academy of Sciences of the United States of America, vol. 108, no. 30, pp. 12431-12436, 2011.

[10] J. M. Woof and D. R. Burton, "Human antibody-Fc receptor interactions illuminated by crystal structures," Nature Reviews Immunology, vol. 4, no. 2, pp. 89-99, 2004.

[11] W. L. Martin, A. P. West Jr., L. Gan, and P. J. Bjorkman, "Crystal structure at $2.8 \AA$ of an FcRn/heterodimeric Fc complex: mechanism of pH-dependent binding," Molecular Cell, vol. 7, no. 4, pp. 867-877, 2001.

[12] E. S. Ward, "Acquiring maternal immunoglobulin: different receptors, similar functions," Immunity, vol. 20, no. 5, pp. 507508, 2004.

[13] C. S. Kaetzel, “The polymeric immunoglobulin receptor: bridging innate and adaptive immune responses at mucosal surfaces," Immunological Reviews, vol. 206, no. 1, pp. 83-99, 2005.

[14] M. Acharya, G. Borland, A. L. Edkins et al., "CD23/FceRII: molecular multi-tasking," Clinical and Experimental Immunology, vol. 162, no. 1, pp. 12-23, 2010.

[15] V. B. Klimovich, "IgM and its receptors: structural and functional aspects," Biochemistry, vol. 76, no. 5, pp. 534-549, 2011.

[16] J. M. Woof and M. W. Russell, "Structure and function relationships in IgA," Mucosal Immunology, vol. 4, no. 6, pp. 590-597, 2011.

[17] F.-E. Johansen and C. S. Kaetzel, "Regulation of the polymeric immunoglobulin receptor and IgA transport: new advances in environmental factors that stimulate pIgR expression and its role in mucosal immunity," Mucosal Immunology, vol. 4, no. 6, pp. 598-602, 2011.

[18] F. Kokubu, K. Hinds, R. Litman, M. J. Shamblott, and G. W. Litman, "Extensive families of constant region genes in a phylogenetically primitive vertebrate indicate an additional level of immunoglobulin complexity," Proceedings of the National Academy of Sciences of the United States of America, vol. 84, no. 16, pp. 5868-5872, 1987.

[19] A. S. Greenberg, A. L. Hughes, J. Guo, D. Avila, E. C. McKinney, and M. F. Flajnik, "A novel "chimeric" antibody class in cartilaginous fish: IgM may not be the primordial immunoglobulin," European Journal of Immunology, vol. 26, no. 5, pp. 1123-1129, 1996.

[20] H. Dooley and M. F. Flajnik, "Shark immunity bites back: affinity maturation and memory response in the nurse shark, Ginglymostoma cirratum," European Journal of Immunology, vol. 35, no. 3, pp. 936-945, 2005.
[21] S. F. Schluter, R. M. Bernstein, and J. J. Marchalonis, "Molecular origins and evolution of immunoglobulin heavy-chain genes of jawed vertebrates," Immunology Today, vol. 18, no. 11, pp. 543549, 1997.

[22] Y. Ohta and M. Flajnik, "IgD, like IgM, is a primordial immunoglobulin class perpetuated in most jawed vertebrates," Proceedings of the National Academy of Sciences of the United States of America, vol. 103, no. 28, pp. 10723-10728, 2006.

[23] S. Fillatreau, A. Six, S. Magadan, R. Castro, J. O. Sunyer, and P. Boudinot, "The astonishing diversity of Ig classes and B cell repertoires in teleost fish," Frontiers in Immunology, vol. 4, no. 28, 2013.

[24] W. Harriman, H. Völk, N. Defranoux, and M. Wabl, "Immunoglobulin class switch recombination," Annual Review of Immunology, vol. 11, pp. 361-384, 1993.

[25] J. Stavnezer and C. T. Amemiya, "Evolution of isotype switching," Seminars in Immunology, vol. 16, no. 4, pp. 257-275, 2004.

[26] V. M. Barreto, Q. Pan-Hammarstrom, Y. Zhao, L. Hammarstrom, Z. Misulovin, and M. C. Nussenzweig, "AID from bony fish catalyzes class switch recombination," Journal of Experimental Medicine, vol. 202, no. 6, pp. 733-738, 2005.

[27] T. C. Fletcher and A. White, "Antibody production in the plaice (Pleuronectes platessa L.) after oral and parenteral immunization with Vibrio anguillarum antigens," Aquaculture, vol. 1, pp. 417-428, 1972.

[28] J. W. H. M. Rombout, L. J. Blok, C. H. J. Lamers, and E. Egberts, "Immunization of carp (Cyprinus carpio) with a Vibrio anguillarum bacterin: indications for a common mucosal immune system," Developmental and Comparative Immunology, vol. 10, no. 3, pp. 341-351, 1986.

[29] U. Georgopoulou and J.-M. Vernier, "Local immunological response in the posterior intestinal segment of the rainbow trout after oral administration of macromolecules," Developmental and Comparative Immunology, vol. 10, no. 4, pp. 529-537, 1986.

[30] C. J. Lobb, "Secretory immunity induced in catfish, Ictalurus punctatus, following bath immunization," Developmental and Comparative Immunology, vol. 11, no. 4, pp. 727-738, 1987.

[31] J. D. Hansen, E. D. Landis, and R. B. Phillips, "Discovery of a unique $\operatorname{Ig}$ heavy-chain $(\operatorname{IgT})$ in rainbow trout: implications for a distinctive B cell developmental pathway in teleost fish," Proceedings of the National Academy of Sciences of the United States of America, vol. 102, no. 19, pp. 6919-6924, 2005.

[32] N. Danilova, J. Bussmann, K. Jekosch, and L. A. Steiner, “The immunoglobulin heavy-chain locus in zebrafish: identification and expression of a previously unknown isotype, immunoglobulin Z," Nature Immunology, vol. 6, no. 3, pp. 295-302, 2005.

[33] R. Savan, A. Aman, K. Sato, R. Yamaguchi, and M. Sakai, "Discovery of a new class of immunoglobulin heavy chain from fugu," European Journal of Immunology, vol. 35, no. 11, pp. 33203331, 2005.

[34] R. Savan, A. Aman, M. Nakao, H. Watanuki, and M. Sakai, "Discovery of a novel immunoglobulin heavy chain gene chimera from common carp (Cyprinus carpio L.)," Immunogenetics, vol. 57, no. 6, pp. 458-463, 2005.

[35] F. Gambón-Deza, C. Sánchez-Espinel, and S. MagadánMompó, "Presence of an unique IgT on the IGH locus in threespined stickleback fish (Gasterosteus aculeatus) and the very recent generation of a repertoire of VH genes," Developmental and Comparative Immunology, vol. 34, no. 2, pp. 114-122, 2010.

[36] T. M. Tadiso, K. K. Lie, and I. Hordvik, "Molecular cloning of IgT from Atlantic salmon, and analysis of the relative expression 
of $\tau, \mu$ and $\delta$ in different tissues," Veterinary Immunology and Immunopathology, vol. 139, no. 1, pp. 17-26, 2011.

[37] S. Mashoof, C. Pohlenz, P. L. Chen et al., "Expressed $\operatorname{IgH} \mu$ and $\tau$ transcripts share diversity segment in ranched Thunnus orientalis," Developmental and Comparative Immunology, vol. 43, no. 1, pp. 76-86, 2014.

[38] Y.-A. Zhang, I. Salinas, J. Li et al., "IgT, a primitive immunoglobulin class specialized in mucosal immunity," Nature Immunology, vol. 11, no. 9, pp. 827-835, 2010.

[39] S. Magadán-Mompó, C. Sánchez-Espinel, and F. GambónDeza, "Immunoglobulin heavy chains in medaka (Oryzias latipes)," BMC Evolutionary Biology, vol. 11, no. 1, article 165, 2011.

[40] C. T. Amemiya, J. Alfoldi, A. P. Lee et al., "The African coelacanth genome provides insights into tetrapod evolution," Nature, vol. 496, no. 7445, pp. 311-316, 2013.

[41] T. Ota, J. P. Rast, G. W. Litman, and C. T. Amemiya, "Lineagerestricted retention of a primitive immunoglobulin heavy chain isotype within the Dipnoi reveals an evolutionary paradox," Proceedings of the National Academy of Sciences of the United States of America, vol. 100, no. 5, pp. 2501-2506, 2003.

[42] Y. Sun, Z. Wei, N. Li, and Y. Zhao, "A comparative overview of immunoglobulin genes and the generation of their diversity in tetrapods," Developmental and Comparative Immunology, vol. 39, no. 1-2, pp. 103-109, 2013.

[43] I. Hadji-Azimi, "Anuran immunoglobulins: a review," Developmental and Comparative Immunology, vol. 3, no. 2, pp. 223-243, 1979.

[44] E. Hsu, M. F. Flajnik, and L. du Pasquier, "A third immunoglobulin class in amphibians," The Journal of Immunology, vol. 135, no. 3, pp. 1998-2004, 1985.

[45] C. T. Amemiya, R. N. Haire, and G. W. Litman, "Nucleotide sequence of a cDNA encoding a third distinct Xenopus immunoglobulin heavy chain isotype," Nucleic Acids Research, vol. 17, no. 13, p. 5388, 1989.

[46] R. Mußmann, M. Wilson, A. Marcuz, M. Courtet, and L. du Pasquier, "Membrane exon sequences of the three Xenopus Ig classes explain the evolutionary origin of mammalian isotypes," European Journal of Immunology, vol. 26, no. 2, pp. 409-414, 1996.

[47] R. Mußmann, L. du Pasquier, and E. Hsu, "Is Xenopus IgX an analog of IgA?” European Journal of Immunology, vol. 26, no. 12, pp. 2823-2830, 1996.

[48] B. Schaerlinger and J.-P. Frippiat, "IgX antibodies in the urodele amphibian Ambystoma mexicanum," Developmental and Comparative Immunology, vol. 32, no. 8, pp. 908-915, 2008.

[49] B. Schaerlinger, M. Bascove, and J.-P. Frippiat, "A new isotype of immunoglobulin heavy chain in the urodele amphibian Pleurodeles walt predominantly expressed in larvae," Molecular Immunology, vol. 45, no. 3, pp. 776-786, 2008.

[50] S. Mashoof, A. Goodroe, C. C. Du et al., "Ancient Tindependence of mucosal IgX/A: gut microbiota unaffected by larval thymectomy in Xenopus laevis," Mucosal Immunology, vol. 6, no. 2, pp. 358-368, 2013.

[51] J. P. Vaerman, J. Picard, and J. F. Heremans, "Structural data on chicken IgA and failure to identify the IgA of the tortoise," in Immunologic Phylogeny, vol. 64 of Advances in Experimental Medicine and Biology, pp. 185-195, Springer, New York, NY, USA, 1975.

[52] J. L. Portis and J. E. Coe, "IgM the secretory immunoglobulin of reptiles and amphibians," Nature, vol. 258, no. 5535, pp. 547$548,1975$.
[53] J. E. Coe, D. Leong, J. L. Portis, and L. A. Thomas, "Immune response in the garter snake (Thamnophis ordinoides)," Immunology, vol. 31, no. 3, pp. 417-424, 1976.

[54] D. Hädge and H. Ambrosius, "Evolution of low molecular weight immunoglobulins-IV. IgY-like immunoglobulins of birds, reptiles and amphibians, precursors of mammalian IgA," Molecular Immunology, vol. 21, no. 8, pp. 699-707, 1984.

[55] D. Hädge and H. Ambrosius, "Evolution of low molecular weight immunoglobulins V. Degree of antigenic relationship between the $7 \mathrm{~S}$ immunoglobulins of mammals, birds, and lower vertebrates to the turkey IgY," Developmental and Comparative Immunology, vol. 10, no. 3, pp. 377-385, 1986.

[56] S. Magadan-Mompo, C. Sanchez-Espinel, and F. GambonDeza, "Immunoglobulin genes of the turtles," Immunogenetics, vol. 65, no. 3, pp. 227-237, 2013.

[57] Z. Wei, Q. Wu, L. Ren et al., "Expression of IgM, IgD, and IgY in a reptile, Anolis carolinensis," The Journal of Immunology, vol. 183, no. 6, pp. 3858-3864, 2009.

[58] F. Gambón-Deza, C. Sánchez-Espinel, and J. V. Beneitez, "A novel IgA-like immunoglobulin in the reptile Eublepharis macularius," Developmental and Comparative Immunology, vol. 31, no. 6, pp. 596-605, 2007.

[59] G. Cheng, Y. Gao, T. Wang et al., "Extensive diversification of IgH subclass-encoding genes and IgM subclass switching in crocodilians," Nature Communications, vol. 4, article 1337, 2013.

[60] S. Magadan-Mompo, C. Sanchez-Espinel, and F. GambonDeza, "IgH loci of American alligator and saltwater crocodile shed light on IgA evolution," Immunogenetics, vol. 65, no. 7, pp. 531-541, 2013.

[61] E. Orlans and M. E. Rose, "An IgA-like immunoglobulin in the fowl," Immunochemistry, vol. 9, no. 8, pp. 833-838, 1972.

[62] G. A. Leslie and L. N. Martin, "Studies on the secretory immunologic system of fowl. 3. Serum and secretory $\operatorname{IgA}$ of the chicken," The Journal of Immunology, vol. 110, no. 1, pp. 1-9, 1973.

[63] J. Bienenstock, D. Y. Perey, J. Gauldie, and B. J. Underdown, "Chicken $\gamma$ A: physicochemical and immunochemical characteristics," The Journal of Immunology, vol. 110, no. 2, pp. 524-533, 1973.

[64] A. M. Lebacq-Verheyden, J. P. Vaerman, and J. F. Heremans, "Quantification and distribution of chicken immunoglobulins IgA, IgM and IgG in serum and secretions," Immunology, vol. 27, no. 4, pp. 683-692, 1974.

[65] J. Goudswaard, A. Noordzij, R. H. van Dam, J. A. vander Donk, and J. P. Vaerman, "The immunoglobulins of the turkey (Meleagris gallopavo). Isolation and characterization of IgG, IgM and IgA in body fluids, eggs and intraocular tissues," Poultry science, vol. 56, no. 6, pp. 1847-1851, 1977.

[66] D. Hadge and H. Ambrosius, "Comparative studies on the structure of biliary immunoglobulins of some avian species. II. Antigenic properties of the biliary immunoglobulins of chicken, turkey, duck and goose," Developmental and Comparative Immunology, vol. 12, no. 2, pp. 319-329, 1988.

[67] J. Goudswaard, J. P. Vaerman, and J. F. Heremans, “Three immunoglobulin classes in the pigeon (Columbia livia)," International Archives of Allergy and Applied Immunology, vol. 53, no. 5, pp. 409-419, 1977.

[68] P. L. K. Ng and D. A. Higgins, "Bile immunoglobulin of the duck (Anas platyrhynchos). I. Preliminary characterization and ontogeny," Immunology, vol. 58, no. 2, pp. 323-327, 1986.

[69] K. E. Magor, G. W. Warr, Y. Bando, D. L. Middleton, and D. A. Higgins, "Secretory immune system of the duck (Anas 
platyrhynchos). Identification and expression of the genes encoding $\operatorname{Ig} \mathrm{A}$ and $\operatorname{IgM}$ heavy chains," European Journal of Immunology, vol. 28, no. 3, pp. 1063-1068, 1998.

[70] Y. Zhao, H. Rabbani, A. Shimizu, and L. Hammarström, "Mapping of the chicken immunoglobulin heavy-chain constant region gene locus reveals an inverted $\alpha$ gene upstream of a condensed $v$ gene," Immunology, vol. 101, no. 3, pp. 348-353, 2000.

[71] M. L. Lundqvist, D. L. Middleton, S. Hazard, and G. W. Warr, "The immunoglobulin heavy chain locus of the duck: genomic organization and expression of $\mathrm{D}, \mathrm{J}$, and $\mathrm{C}$ region genes," The Journal of Biological Chemistry, vol. 276, no. 50, pp. 4672946736, 2001.

[72] T. Huang, M. Zhang, Z. Wei et al., "Analysis of immunoglobulin transcripts in the ostrich Struthio camelus, a primitive avian species," PLoS ONE, vol. 7, no. 3, Article ID e34346, 2012.

[73] K. H. Roux, "Immunoglobulin structure and function as revealed by electron microscopy," International Archives of Allergy and Immunology, vol. 120, no. 2, pp. 85-99, 1999.

[74] F. Gambón-Deza, C. Sánchez-Espinel, and S. MagadánMompó, "The immunoglobulin heavy chain locus in the platypus (Ornithorhynchus anatinus)," Molecular Immunology, vol. 46, no. 13, pp. 2515-2523, 2009.

[75] Y. Zhao, H. Cui, C. M. Whittington et al., "Ornithorhynchus anatinus (platypus) links the evolution of immunoglobulin genes in eutherian mammals and nonmammalian tetrapods," The Journal of Immunology, vol. 183, no. 5, pp. 3285-3293, 2009.

[76] M. Aveskogh and L. Hellman, "Evidence for an early appearance of modern post-switch isotypes in mammalian evolution, cloning of IgE, IgG and IgA from the marsupial Monodelphis domestica," European Journal of Immunology, vol. 28, no. 9, pp. 2738-2750, 1998.

[77] K. Belov, G. A. Harrison, and D. W. Cooper, "Molecular cloning of the cDNA encoding the constant region of the immunoglobulin a heavy chain $(\mathrm{C} \alpha)$ from a marsupial: Trichosurus vulpecula (common brushtail possum)," Immunology Letters, vol. 60, no. 2-3, pp. 165-170, 1998.

[78] K. Belov, K. R. Zenger, L. Hellman, and D. W. Cooper, "Echidna IgA supports mammalian unity and traditional Therian relationship," Mammalian Genome, vol. 13, no. 11, pp. 656-663, 2002.

[79] K. Belov and L. Hellman, "Immunoglobulin genetics of Ornithorhynchus anatinus (platypus) and Tachyglossus aculeatus (short-beaked echidna)," Comparative Biochemistry and Physiology, vol. 136, no. 4, pp. 811-819, 2003.

[80] M. Vernersson, M. Aveskogh, B. Munday, and L. Hellman, "Evidence for an early appearance of modern post-switch immunoglobulin isotypes in mammalian evolution (II), cloning of IgE, IgG1 and IgG2 from a monotreme, the duck-billed platypus, Ornithorhynchus anatinus," European Journal of Immunology, vol. 32, no. 8, pp. 2145-2155, 2002.

[81] C. Auffray, R. Nageotte, and J. L. Sikorav, "Mouse immunoglobulin A: nucleotide sequence of the structural gene for the $\alpha$ heavy chain derived from cloned cDNAs," Gene, vol. 13, no. 4, pp. 365-374, 1981.

[82] T. Ukaji, D. Sumiyama, and O. Kai, "Sequence determination of the heavy-chain constant region in four immunoglobulin classes of Mongolian gerbils (Meriones unguiculatus)," Experimental Animals, vol. 61, no. 2, pp. 99-107, 2012.

[83] R. C. Burnett, W. C. Hanly, S. K. Zhai, and K. L. Knight, "The IgA heavy chain gene family in rabbit: cloning and sequence analysis of $13 \mathrm{C} \alpha$ genes," The EMBO Journal, vol. 8, no. 13, pp. 4041-4047, 1989.

[84] D. K. Lanning, S.-K. Zhai, and K. L. Knight, "Analysis of the $3^{\prime}$ $\mathrm{C} \mu$ region of the rabbit Ig heavy chain locus," Gene, vol. 309, no. 2, pp. 135-144, 2003.

[85] F. Ros, J. Puels, N. Reichenberger, W. van Schooten, R. Buelow, and J. Platzer, "Sequence analysis of $0.5 \mathrm{Mb}$ of the rabbit germline immunoglobulin heavy chain locus," Gene, vol. 330, no. 1-2, pp. 49-59, 2004.

[86] M. Patel, D. Selinger, G. E. Mark, G. J. Hickey, and G. F. Hollis, "Sequence of the dog immunoglobulin alpha and epsilon constant region genes," Immunogenetics, vol. 41, no. 5, pp. 282 286, 1995.

[87] Z. Zhao, Y. Zhao, Q. Pan-Hammarström et al., "Physical mapping of the giant panda immunoglobulin heavy chain constant region genes," Developmental and Comparative Immunology, vol. 31, no. 10, pp. 1034-1049, 2007.

[88] W. R. Brown and J. E. Butler, "Characterization of a C $\alpha$ gene of swine," Molecular Immunology, vol. 31, no. 8, pp. 633-642, 1994.

[89] W. R. Brown, H. Rabbani, J. E. Butler, and L. Hammarström, "Characterization of the bovine $\mathrm{C} \alpha$ gene," Immunology, vol. 91, no. 1, pp. 1-6, 1997.

[90] G. P. White, P. Roche, M. R. Brandon, S. E. Newton, and E. N. T. Meeusen, "Cloning and characterization of sheep (Ovis aries) immunoglobulin $\alpha$ chain," Immunogenetics, vol. 48, no. 5, pp. 359-362, 1998.

[91] A. Mancia, T. A. Romano, H. A. Gefroh et al., "Characterization of the immunoglobulin A heavy chain gene of the Atlantic bottlenose dolphin (Tursiops truncatus)," Veterinary Immunology and Immunopathology, vol. 118, no. 3-4, pp. 304-309, 2007.

[92] B. Wagner, I. Greiser-Wilke, and D. F. Antczak, "Characterization of the horse [Equus caballus] IGHA gene," Immunogenetics, vol. 55, no. 8, pp. 552-560, 2003.

[93] N. Takahashi, S. Ueda, and M. Obata, "Structure of human immunoglobulin gamma genes: implications for evolution of a gene family," Cell, vol. 29, no. 2, pp. 671-679, 1982.

[94] J. G. Flanagan, M.-P. Lefranc, and T. H. Rabbitts, "Mechanisms of divergence and convergence of the human immunoglobulin $\alpha 1$ and $\alpha 2$ constant region gene sequences," Cell, vol. 36 , no. 3 , pp. 681-688, 1984.

[95] S. Kawamura, K. Omoto, and S. Ueda, "Evolutionary hypervariability in the hinge region of the immunoglobulin alpha gene," Journal of Molecular Biology, vol. 215, no. 2, pp. 201-206, 1990.

[96] F. Scinicariello, F. Masseoud, L. Jayashankar, and R. Attanasio, "Sooty mangabey (Cercocebus torquatus atys) IGHG and IGHA genes," Immunogenetics, vol. 58, no. 12, pp. 955-965, 2006.

[97] K. A. Rogers, L. Jayashankar, F. Scinicariello, and R. Attanasio, "Nonhuman primate IgA: genetic heterogeneity and interactions with CD89," The Journal of Immunology, vol. 180, no. 7, pp. 4816-4824, 2008.

[98] S. Kawamura, N. Saitou, and S. Ueda, "Concerted evolution of the primate immunoglobulin $\alpha$-gene through gene conversion," The Journal of Biological Chemistry, vol. 267, no. 11, pp. 73597367, 1992.

[99] S. Kawamura and S. Ueda, "Immunoglobulin $\mathrm{C}_{H}$ gene family in hominoids and its evolutionary history," Genomics, vol. 13, no. 1, pp. 194-200, 1992.

[100] A. Brusco, U. Cariota, A. Bottaro et al., "Structural and immunologic analysis of gene triplications in the Ig heavy chain constant region locus," The Journal of Immunology, vol. 152, no. 1, pp. 129-135, 1994. 
[101] H. Rabbani, Q. Pan, N. Kondo, C. I. E. Smith, and L. Hammarström, "Duplications and deletions of the human IGHC locus: evolutionary implications," Immunogenetics, vol. 45, no. 2, pp. 136-141, 1996.

[102] P. F. Weinheimer, J. Mestecky, and R. T. Acton, "Species distribution of J chain," The Journal of Immunology, vol. 107, no. 4, pp. 1211-1212, 1971.

[103] F. P. Inman and J. Mestecky, "The J chain of polymeric immunoglobulins," in Contemporary Topics in Molecular Immunology, vol. 3, pp. 111-141, Springer, New York, NY, USA, 1974.

[104] P. Brandtzaeg, "Presence of J chain in human immunocytes containing various immunoglobulin classes," Nature, vol. 252, no. 5482, pp. 418-420, 1974.

[105] L. Tacchi, E. Larragoite, and I. Salinas, "Discovery of J chain in African lungfish (Protopterus dolloi, Sarcopterygii) using high throughput transcriptome sequencing: implications in mucosal immunity," PLoS ONE, vol. 8, no. 8, Article ID e70650, 2013.

[106] I. K. Zarkadis, D. Mastellos, and J. D. Lambris, "Phylogenetic aspects of the complement system," Developmental and Comparative Immunology, vol. 25, no. 8-9, pp. 745-762, 2001.

[107] A. P. West Jr., A. B. Herr, and P. J. Bjorkman, "The chicken yolk sac IgY receptor, a functional equivalent of the mammalian MHC-related Fc receptor, is a phospholipase $A_{2}$ receptor homolog," Immunity, vol. 20, no. 5, pp. 601-610, 2004.

[108] D. B. Tesar, E. J. Cheung, and P. J. Bjorkman, "The chicken yolk sac IgY receptor, a mammalian mannose receptor family member, transcytoses IgY across polarized epithelial cells," Molecular Biology of the Cell, vol. 19, no. 4, pp. 1587-1593, 2008.

[109] A. I. Taylor, R. L. Beavil, B. J. Sutton, and R. A. Calvert, "A monomeric chicken IgY receptor binds IgY with 2:1 stoichiometry," The Journal of Biological Chemistry, vol. 284, no. 36, pp. 24168-24175, 2009.

[110] K. Baker, S.-W. Qiao, T. Kuo et al., "Immune and non-immune functions of the (not so) neonatal Fc receptor, FcRn," Seminars in Immunopathology, vol. 31, no. 2, pp. 223-236, 2009.

[111] K. Baker, R. S. Blumberg, and C. S. Kaetzel, "Immunoglobulin transport and immunoglobulin receptors," in Mucosal Immunology, J. Mestecky, W. Strober, H. Cheroutre, B. Kelsall, B. N. Lambrecht, and M. W. Russell, Eds., chapter 20, Academic Press/Elsevier, Waltham, Mass, USA, 2014.

[112] C. S. Kaetzel, “The polymeric immunoglobulin receptor," in eLS, John Wiley \& Sons, Chichester, UK, 2013.

[113] N. J. Mantis, N. Rol, and B. Corthésy, "Secretory IgA’s complex roles in immunity and mucosal homeostasis in the gut," Mucosal Immunology, vol. 4, no. 6, pp. 603-611, 2011.

[114] J. V. Peppard, M. E. Rose, and P. Hesketh, "A functional homologue of mammalian secretory component exists in chickens," European Journal of Immunology, vol. 13, no. 7, pp. 566-570, 1983.

[115] K. E. Mostov, M. Friedlander, and G. Blobel, “The receptor for transepithelial transport of $\operatorname{IgA}$ and $\operatorname{IgM}$ contains multiple immunoglobulin-like domains," Nature, vol. 308, no. 5954, pp. 37-43, 1984.

[116] P. Krajci, R. Solberg, M. Sandberg, O. Oyen, T. Jahnsen, and P. Brandtzaeg, "Molecular cloning of the human transmembrane secretory component (poly-Ig receptor) and its mRNA expression in human tissues," Biochemical and Biophysical Research Communications, vol. 158, no. 3, pp. 783-789, 1989.

[117] P. Krajci, D. Kvale, K. Tasken, and P. Brandtzaeg, "Molecular cloning and exon-intron mapping of the gene encoding human transmembrane secretory component (the poly-Ig receptor),"
European Journal of Immunology, vol. 22, no. 9, pp. 2309-2315, 1992.

[118] J. F. Piskurich, J. A. France, C. M. Tamer, C. A. Willmer, C. S. Kaetzel, and D. M. Kaetzel, "Interferon- $\gamma$ induces polymeric immunoglobulin receptor mRNA in human intestinal epithelial cells by a protein synthesis dependent mechanism," Molecular Immunology, vol. 30, no. 4, pp. 413-421, 1993.

[119] J. F. Piskurich, M. H. Blanchard, K. R. Youngman, J. A. France, and C. S. Kaetzel, "Molecular cloning of the mouse polymeric Ig receptor: functional regions of the molecule are conserved among five mammalian species," The Journal of Immunology, vol. 154, no. 4, pp. 1735-1747, 1995.

[120] M. A. Kulseth, P. Krajci, O. Myklebost, and S. Rogne, "Cloning and characterization of two forms of bovine polymeric immunoglobulin receptor cDNA," DNA and Cell Biology, vol. 14, no. 3, pp. 251-256, 1995.

[121] K. S. Koch, A. S. Gleiberman, T. Aoki et al., "Discordant expression and variable numbers of neighboring GGA- and GAA-rich triplet repeats in the $3^{\prime}$ untranslated regions of two groups of messenger RNAs encoded by the rat polymeric immunoglobulin receptor gene," Nucleic Acids Research, vol. 23, no. 7, pp. 1098-1112, 1995.

[122] F. M. Adamski and J. Demmer, “Two stages of increased IgA transfer during lactation in the marsupial, Trichosurus vulpecula (brushtail possum)," The Journal of Immunology, vol. 162, no. 10, pp. 6009-6015, 1999.

[123] H. Kumura, T. Sone, K.-I. Shimazaki, and E. Kobayashi, "Sequence analysis of porcine polymeric immunoglobulin receptor from mammary epithelial cells present in colostrum," The Journal of Dairy Research, vol. 67, no. 4, pp. 631-636, 2000.

[124] C. L. Taylor, G. A. Harrison, C. M. Watson, and E. M. Deane, "cDNA cloning of the polymeric immunoglobulin receptor of the marsupial Macropus eugenii (tammar wallaby)," European Journal of Immunogenetics, vol. 29, no. 2, pp. 87-93, 2002.

[125] R. Braathen, V. S. Hohman, P. Brandtzaeg, and F.-E. Johansen, "Secretory antibody formation: conserved binding interactions between J chain and polymeric Ig receptor from humans and amphibians," The Journal of Immunology, vol. 178, no. 3, pp. 1589-1597, 2007.

[126] M. J. Lewis, B. Wagner, R. M. Irvine, and J. M. Woof, "IgA in the horse: cloning of equine polymeric Ig receptor and $\mathrm{J}$ chain and characterization of recombinant forms of equine IgA," Mucosal Immunology, vol. 3, no. 6, pp. 610-621, 2010.

[127] A. J. Leon, D. Banner, L. Xu et al., "Sequencing, annotation, and characterization of the influenza ferret infectome," Journal of Virology, vol. 87, no. 4, pp. 1957-1966, 2013.

[128] W. H. Wieland, D. Orzáez, A. Lammers, H. K. Parmentier, M. W. A. Verstegen, and A. Schots, "A functional polymeric immunoglobulin receptor in chicken (Gallus gallus) indicates ancient role of secretory IgA in mucosal immunity," Biochemical Journal, vol. 380, no. 3, pp. 669-676, 2004.

[129] K. Hamuro, H. Suetake, N. R. Saha, K. Kikuchi, and Y. Suzuki, "A teleost polymeric Ig receptor exhibiting two Ig-like domains transports tetrameric IgM into the skin," The Journal of Immunology, vol. 178, no. 9, pp. 5682-5689, 2007.

[130] J. H. W. M. Rombout, S. J. L. van der Tuin, G. Yang et al., "Expression of the polymeric immunoglobulin receptor (pIgR) in mucosal tissues of common carp (Cyprinus carpio L.)," Fish and Shellfish Immunology, vol. 24, no. 5, pp. 620-628, 2008.

[131] L.-N. Feng, D.-Q. Lu, J.-X. Bei et al., "Molecular cloning and functional analysis of polymeric immunoglobulin receptor gene 
in orange-spotted grouper (Epinephelus coioides)," Comparative Biochemistry and Physiology B, vol. 154, no. 3, pp. 282-289, 2009.

[132] A. E. Østergaard, S. A. M. Martin, T. Wang, R. J. M. Stet, and C. J. Secombes, "Rainbow trout (Oncorhynchus mykiss) possess multiple novel immunoglobulin-like transcripts containing either an ITAM or ITIMs," Developmental and Comparative Immunology, vol. 33, no. 4, pp. 525-532, 2009.

[133] H. Eiffert, E. Quentin, and J. Decker, “The primary structure of the human free secretory component and the arrangement of disulfide bonds," Hoppe-Seyler's Zeitschrift fur Physiologische Chemie, vol. 365, no. 12, pp. 1489-1495, 1984.

[134] E. Fallgreen-Gebauer, W. Gebauer, A. Bastian et al., "The covalent linkage of secretory component to IgA. Structure of sIgA," Biological Chemistry Hoppe-Seyler, vol. 374, no. 11, pp. 10231028, 1993.

[135] J. M. Woof, "The structure of IgA," in Mucosal Immune Defense: Immunoglobulin A, C. S. Kaetzel, Ed., chapter 1, pp. 1-24, Springer, New York, NY, USA, 2007.

[136] A. Bonner, A. Almogren, P. B. Furtado, M. A. Kerr, and S. J. Perkins, "Location of secretory component on the Fc edge of dimeric IgA1 reveals insight into the role of secretory IgA1 in mucosal immunity," Mucosal Immunology, vol. 2, no. 1, pp. 7484, 2009.

[137] A. Bonner, A. Almogren, P. B. Furtado, M. A. Kerr, and S. J. Perkins, "The nonplanar secretory IgA2 and near planar secretory IgA1 solution structures rationalize their different mucosal immune responses," The Journal of Biological Chemistry, vol. 284, no. 8, pp. 5077-5087, 2009.

[138] J. Johansen, B. Braathen, and P. Brandtzaeg, "Role of J chain in secretory immunoglobulin formation," Scandinavian Journal of Immunology, vol. 52, no. 3, pp. 240-248, 2000.

[139] B. A. Hendrickson, D. A. Conner, D. J. Ladd et al., "Altered hepatic transport of immunoglobulin A in mice lacking the J chain," Journal of Experimental Medicine, vol. 182, no. 6, pp. 1905-1911, 1995.

[140] B. A. Hendrickson, L. Rindisbacher, B. Corthesy et al., "Lack of association of secretory component with IgA in J chaindeficient mice," The Journal of Immunology, vol. 157, no. 2, pp. 750-754, 1996.

[141] N. Lycke, L. Erlandsson, L. Ekman, K. Schön, and T. Leanderson, "Lack of J chain inhibits the transport of gut IgA and abrogates the development of intestinal antitoxic protection," The Journal of Immunology, vol. 163, no. 2, pp. 913-919, 1999.

[142] F.-E. Johansen, R. Braathen, and P. Brandtzaeg, "The J chain is essential for polymeric Ig receptor-mediated epithelial transport of IgA," The Journal of Immunology, vol. 167, no. 9, pp. 51855192, 2001.

[143] R. E. Ley, D. A. Peterson, and J. I. Gordon, "Ecological and evolutionary forces shaping microbial diversity in the human intestine," Cell, vol. 124, no. 4, pp. 837-848, 2006.

[144] M. McFall-Ngai, "Adaptive immunity: care for the community," Nature, vol. 445, no. 7124, p. 153, 2007.

[145] A. J. Macpherson, K. D. McCoy, F.-E. Johansen, and P. Brandtzaeg, "The immune geography of IgA induction and function," Mucosal Immunology, vol. 1, no. 1, pp. 11-22, 2008.

[146] D. Kvale and P. Brandtzaeg, "Constitutive and cytokine induced expression of HLA molecules, secretory component, and intercellular adhesion molecule-1 is modulated by butyrate in the colonic epithelial cell line HT-29," Gut, vol. 36, no. 5, pp. 737$742,1995$.
[147] L. V. Hooper, M. H. Wong, A. Thelin, L. Hansson, P. G. Falk, and J. I. Gordon, "Molecular analysis of commensal host-microbial relationships in the intestine," Science, vol. 291, no. 5505, pp. 881884, 2001.

[148] S. Hapfelmeier, M. A. E. Lawson, E. Slack et al., "Reversible microbial colonization of germ-free mice reveals the dynamics of IgA immune responses," Science, vol. 328, no. 5986, pp. 17051709, 2010.

[149] D. H. Reikvam, M. Derrien, R. Islam et al., "Epithelial-microbial cross-talk in polymeric Ig receptor deficient mice," European Journal of Immunology, vol. 42, no. 11, pp. 2959-2970, 2012.

[150] E. W. Rogier, A. L. Frantz, M. E. C. Bruno et al., "Secretory antibodies in breast milk promote long-term intestinal homeostasis by regulating the gut microbiota and host gene expression," Proceedings of the National Academy of Sciences of the United States of America, vol. 111, no. 8, pp. 3074-3079, 2014.

[151] G. M. Barton and R. Medzhitov, "Toll-like receptor signaling pathways," Science, vol. 300, no. 5625, pp. 1524-1525, 2003.

[152] K. Takeda and S. Akira, "Toll receptors and pathogen resistance," Cellular Microbiology, vol. 5, no. 3, pp. 143-153, 2003.

[153] E. Cario and D. K. Podolsky, "Differential alteration in intestinal epithelial cell expression of Toll-like receptor 3 (TLR3) and TLR4 in inflammatory bowel disease," Infection and Immunity, vol. 68, no. 12, pp. 7010-7017, 2000.

[154] M. Hausmann, S. Kiessling, S. Mestermann et al., "Toll-like receptors 2 and 4 are up-regulated during intestinal inflammation," Gastroenterology, vol. 122, no. 7, pp. 1987-2000, 2002.

[155] M. T. Abreu, L. S. Thomas, S. Y. Tesfay et al., "Regulation of TLR4 and MD-2 in the intestinal epithelium: evidence for dysregulated LPS signaling in human inflammatory bowel disease," in Proceedings of the 90th Annual Meeting of the American Association for Immunologists, Abstract 36.34, Denver, Colo, USA, 2003.

[156] T. A. Schneeman, M. E. C. Bruno, H. Schjerven, F.-E. Johansen, L. Chady, and C. S. Kaetzel, "Regulation of the polymeric Ig receptor by signaling through TLRs 3 and 4: linking innate and adaptive immune responses," The Journal of Immunology, vol. 175, no. 1, pp. 376-384, 2005.

[157] M. E. C. Bruno, A. L. Frantz, E. W. Rogier, F.-E. Johansen, and C. S. Kaetzel, "Regulation of the polymeric immunoglobulin receptor by the classical and alternative NF- $\kappa \mathrm{B}$ pathways in intestinal epithelial cells," Mucosal Immunology, vol. 4, no. 4, pp. 468-478, 2011.

[158] M. E. C. Bruno, E. W. Rogier, A. L. Frantz, A. T. Stefka, S. N. Thompson, and C. S. Kaetzel, "Regulation of the polymeric immunoglobulin receptor in intestinal epithelial cells by Enterobacteriaceae: implications for mucosal homeostasis," Immunological Investigations, vol. 39, no. 4-5, pp. 356-382, 2010.

[159] A. L. Frantz, E. W. Rogier, C. R. Weber et al., "Targeted deletion of MyD88 in intestinal epithelial cells results in compromised antibacterial immunity associated with downregulation of polymeric immunoglobulin receptor, mucin-2, and antibacterial peptides," Mucosal Immunology, vol. 5, no. 5, pp. 501-512, 2012.

[160] E. W. Rogier, A. L. Frantz, M. E. C. Bruno, and C. S. Kaetzel, "Secretory IgA is concentrated in the outer layer of intestinal mucus along with gut bacteria," Pathogens. In press.

[161] M. B. Geuking, K. D. McCoy, and A. J. Macpherson, “The function of secretory $\operatorname{IgA}$ in the context of the intestinal continuum of adaptive immune responses in host-microbial mutualism," Seminars in Immunology, vol. 24, no. 1, pp. 36-42, 2012. 
[162] L. V. Hooper, D. R. Littman, and A. J. Macpherson, "Interactions between the microbiota and the immune system," Science, vol. 336, no. 6086, pp. 1268-1273, 2012.

[163] A. J. Macpherson, M. B. Geuking, E. Slack, S. Hapfelmeier, and K. D. McCoy, "The habitat, double life, citizenship, and forgetfulness of IgA," Immunological Reviews, vol. 245, no. 1, pp. 132-146, 2012. 


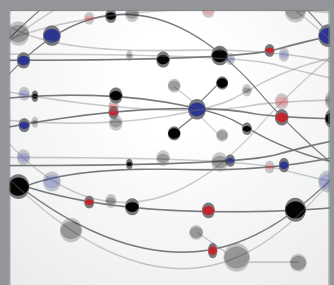

The Scientific World Journal
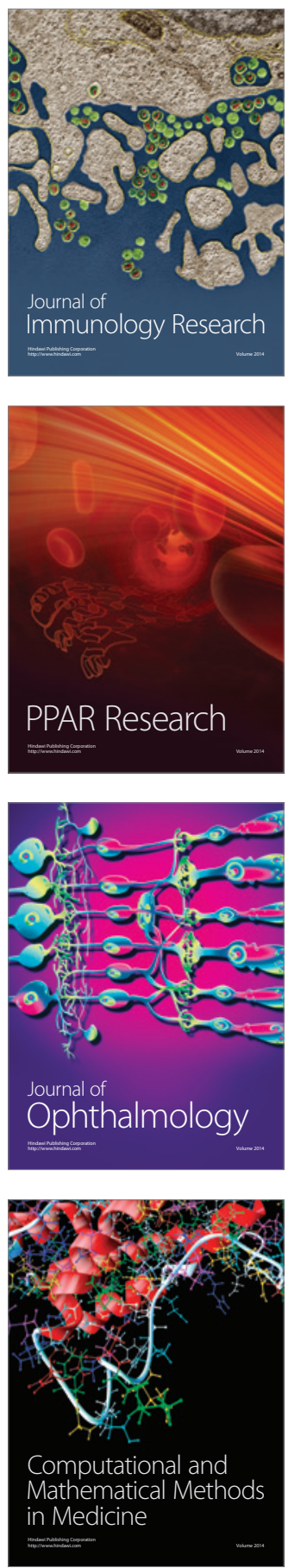

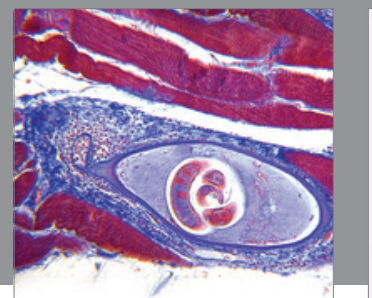

Gastroenterology

Research and Practice
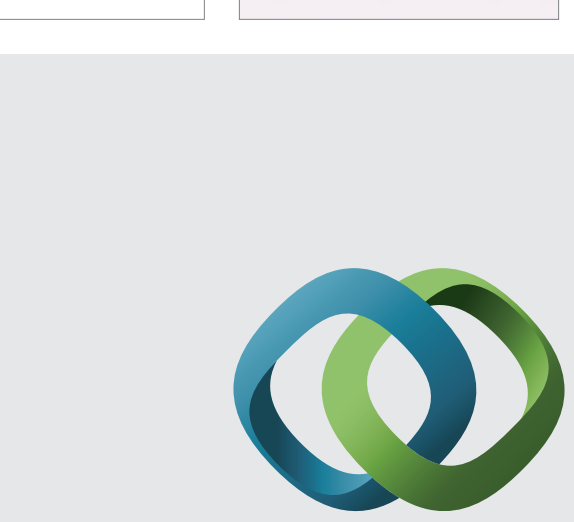

\section{Hindawi}

Submit your manuscripts at

http://www.hindawi.com
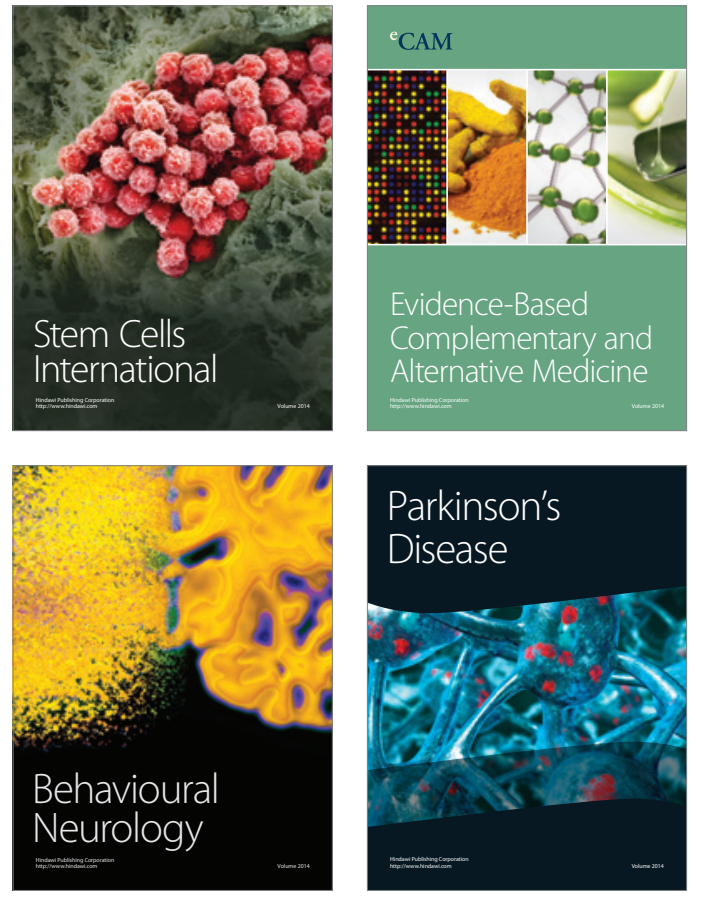
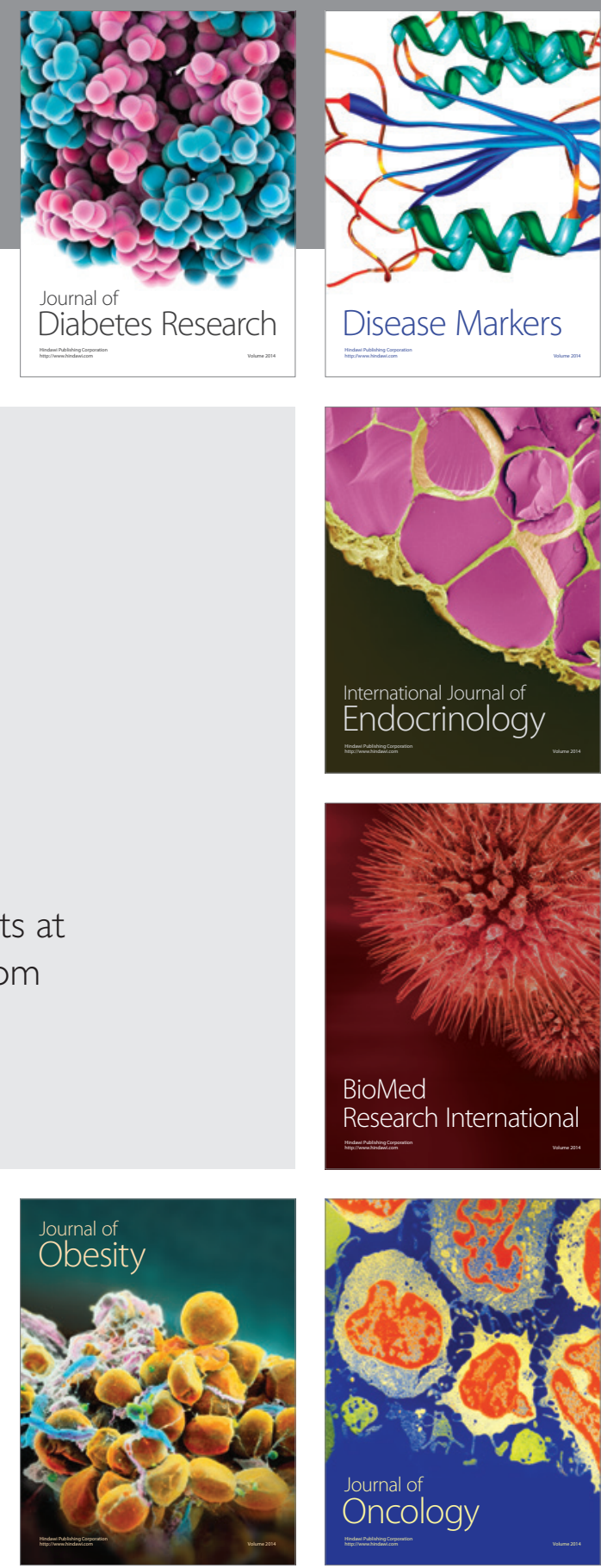

Disease Markers
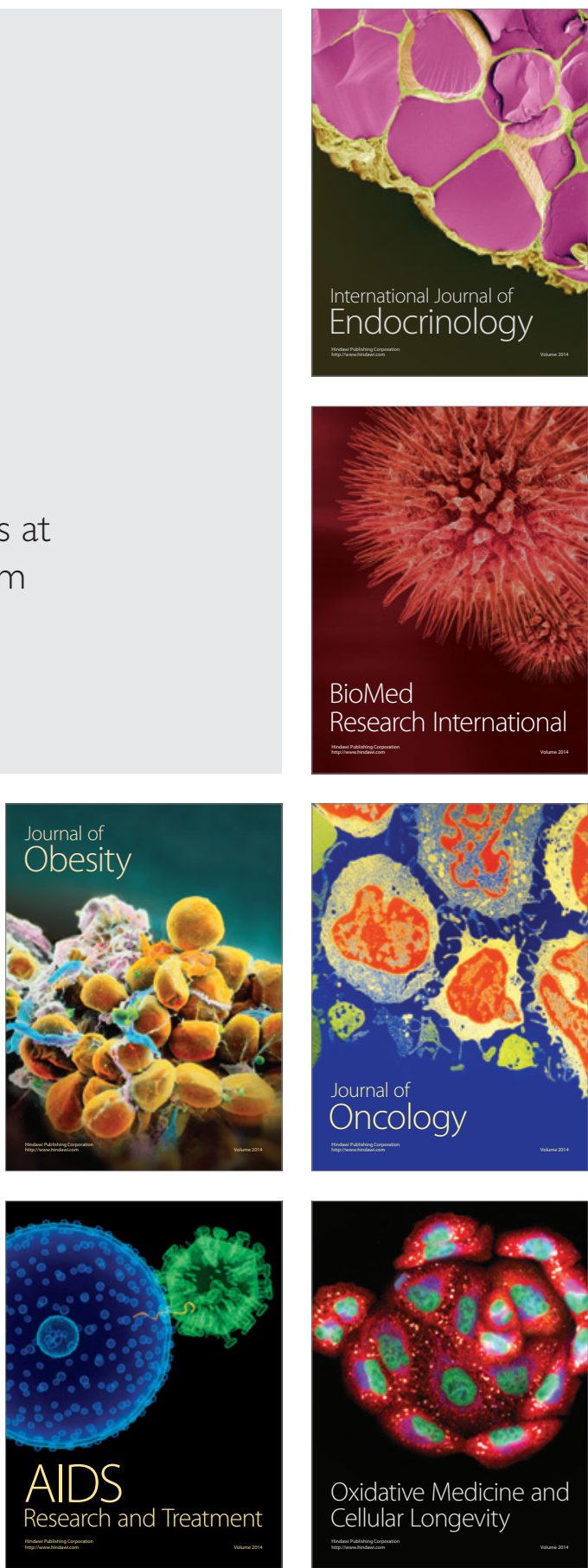